\title{
Non-axis-symmetrical punching shear around internal columns of RC slabs without transverse reinforcement
}

\section{Juan Sagaseta}

Lecturer, University of Surrey, Guildford, UK*

Aurelio Muttoni

Professor, Institut d'ingénierie civile (ENAC), École Polytechnique Fédérale de Lausanne, Switzerland

\section{Miguel Fernández Ruiz}

Lecturer, Institut d'ingénierie civile (ENAC), École Polytechnique Fédérale de Lausanne, Switzerland

Luca Tassinari

PhD student, Institut d'ingénierie civile (ENAC), École Polytechnique Fédérale de Lausanne, Switzerland

Most analytical approaches and available test data for punching shear in flat slabs assume axis-symmetrical conditions, which seems realistic for representing slabs supported on columns equally spaced in both orthogonal directions. However, in practice, there are many instances where loading, geometry and reinforcement around internal columns differ significantly from ideal axis-symmetrical conditions. Typical examples include slab bridges, flat slabs with unequal spans and footings with unequal widths. This paper presents a series of punching shear tests on slabs without transverse reinforcement and different flexural reinforcement ratios or loading conditions in each orthogonal direction. The tests show that both the type of loading and the amount of flexural reinforcement have a significant influence on the punching shear strength and symmetry of the response. Eurocode 2 and BS 8110 code formulas provided reasonable strength predictions of the tests using the recommended average reinforcement ratio between the $x$ and $y$ directions. A physical explanation behind this assumption is presented, based on critical shear crack theory. A rational analytical approach was developed for non-axis-symmetrical punching, which provides accurate predictions of strength and deformation capacity. The novelty of the proposed method is that it considers a non-uniform shear strength distribution per unit length along the control perimeter, which results in a redistribution of shear near failure.

\section{Notation}

$b_{0} \quad$ length of control perimeter

$b_{x}, b_{y} \quad$ segment of control perimeter corresponding to $x$ and $y$ directions

$c \quad$ side of the column

$d \quad$ average effective depth of the slab

$d_{\text {avg }} \quad$ average distance measured from the bottom of the slab to the contact between reinforcement bars in the $x$ and $y$ directions

$d_{\mathrm{g}} \quad$ maximum diameter of the aggregate

$E_{\mathrm{s}} \quad$ modulus of elasticity of reinforcement

$f_{\mathrm{c}} \quad$ concrete cylinder strength

$f_{\text {cu }} \quad$ concrete cube strength

$f_{\mathrm{y}} \quad$ yield strength of flexural reinforcement

$L \quad$ span length

$r_{\mathrm{s}} \quad$ radius of isolated axis-symmetrical element

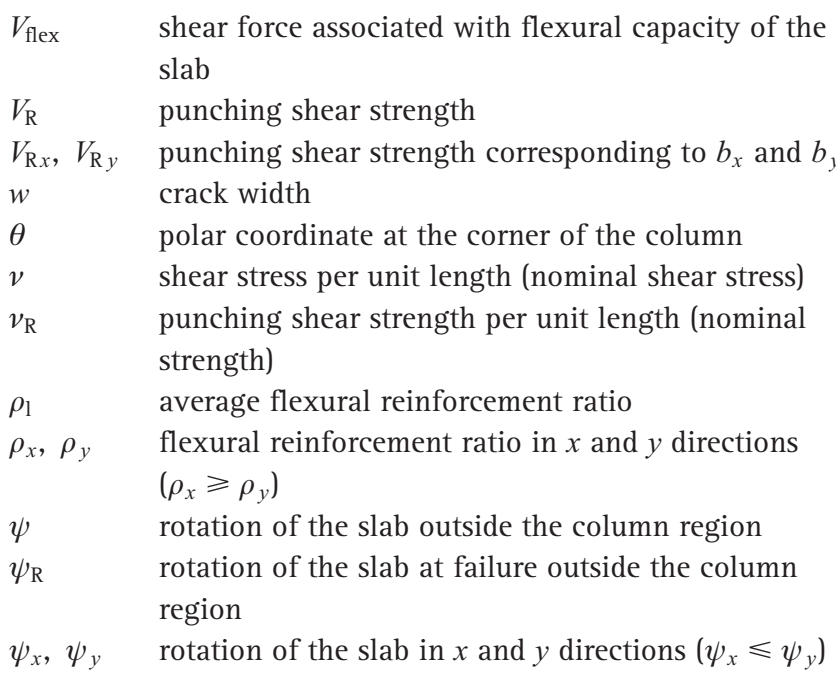

\section{Introduction}

The design of reinforced concrete flat slabs is generally governed in the ultimate limit states by punching shear around concentrated 
loads or columns. The development of rational design formulas for punching shear is problematic since it is a three-dimensional problem and several simplifications are thus generally adopted. For example, analytical models for punching such as the classical model of Kinnunen and Nylander (1960) or the more recent critical shear crack theory (CSCT) proposed by Muttoni (2008) assume axis-symmetrical conditions. These models consider equilibrium and kinematics relationships on an isolated axissymmetrical element (Figure 1(a)). The radius of the element $r_{\mathrm{s}}$ is typically taken as $0 \cdot 22 \mathrm{~L}$, which corresponds to the line of contraflexure in a flat slab with similar spans $L$ in both directions according to a linear-elastic analysis.

The design codes Eurocode 2 (EC2) (BSI, 2004) and BS 8110 (BSI, 1997) propose empirical design equations for estimating the punching shear strength in slabs without transverse reinforcement; they are the same equations applied for one-way shear. The punching shear strength per unit length (i.e. the nominal strength $\left.v_{\mathrm{R}}\right)$ is assumed to be constant for the entire control perimeter $\left(b_{0}\right)$ around internal columns with balanced moments. The EC2 and BS 8110 formulas are written in terms of the concrete compressive strength, the reinforcement ratio in both orthogonal directions $\left(\rho_{x}\right.$ and $\rho_{y}$ ) and size effect factors. ACI 318-08 (ACI, 2008) adopts a simpler relationship in which the flexural reinforcement and size effect are neglected and the normalised shear strength $V_{\mathrm{R}} /\left(b_{0} d f_{\mathrm{c}}^{1 / 2}\right)$ is thus constant. ACI 318-08 reduces the allowable stress for large and rectangular columns $\left(b_{0} / d>20\right.$ or $c_{\max } /$ $\left.c_{\min }>2\right)$ by a factor $\alpha$, which is the lowest of $1,\left(0 \cdot 5+c_{\min } / c_{\max }\right)$ and $\left(0 \cdot 5+10 d / b_{0}\right)$ for internal columns.

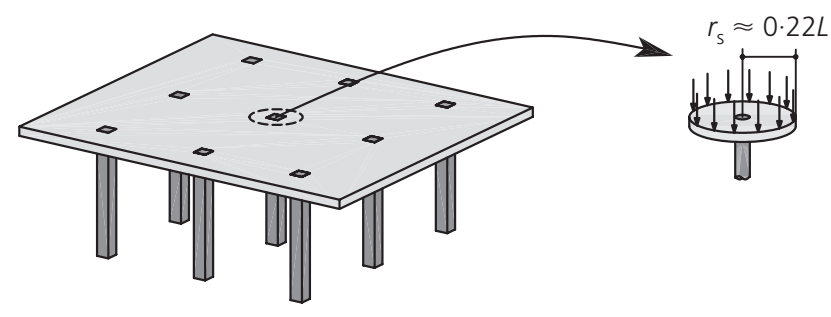

(a)

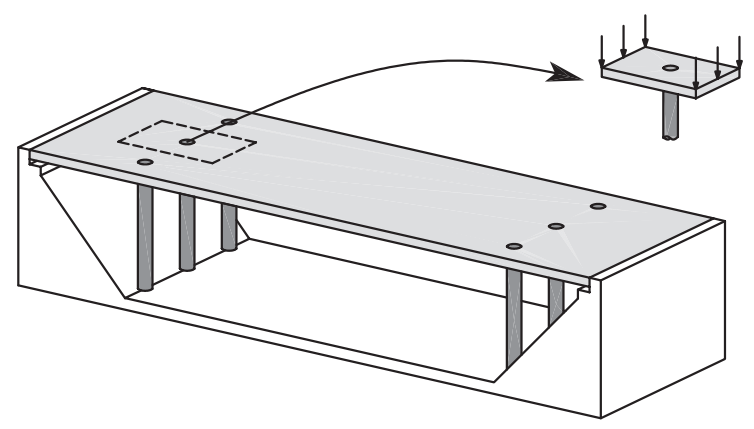

(b)

Figure 1. Punching shear in (a) flat slabs with square bays (axis-symmetrical conditions) and (b) slab bridges (non-axis-symmetrical conditions)
With respect to punching in non-axis-symmetrical conditions, theoretical or empirical approaches usually extend the axissymmetrical formulation by correcting it with a series of factors. Reworking of the theoretical ground is typically not performed. In practice, however, most punching shear cases correspond to non-axis-symmetrical punching. This refers to slabs where bending deformations are non-axis-symmetrical around the column; this depends on several factors, not just the type of loading as is generally assumed. Three groups of design situations can be recognised that lead to non-axis-symmetrical punching around internal columns, namely non-axis-symmetry due to:

(a) loading

(b) slab and column geometry

(c) reinforcement layout.

Asymmetry due to loading can result from eccentricity of the load (i.e. moment transfer) or from one-way spanning with balanced moments (Figure 1(b)). Geometric conditions can lead to non-symmetrical punching such as columns with irregular shapes (e.g. rectangular columns) or slabs with openings near the column. Lastly, slabs with uneven span lengths in the $x$ and $y$ directions, as shown in Figure 1(b), typically have non-symmetrical reinforcement layouts with different flexural reinforcement ratios in each orthogonal direction $\left(\rho_{x} \neq \rho_{y}\right)$.

This paper focuses mainly on cases where $\rho_{x}$ and $\rho_{y}$ are significantly different for which experimental and analytical work is limited. The performance of EC2 (BSI, 2004), BS 8110 (BSI, 1997) and ACI 318-08 (ACI, 2008) formulas for punching shear is investigated for such cases using experimental data presented in this paper. A model based on the CSCT is developed that provides a better understanding of the problem and gives a physical explanation behind the assumptions made in EC2 and BS 8110 formulas with $\rho_{x} \neq \rho_{y}$.

\section{Punching shear tests with non-symmetrical flexural reinforcement}

It is generally believed that slabs with a conventional orthogonal reinforcement layout behave axis-symmetrically in terms of deflections and distribution of shear forces around the control perimeter, regardless of whether the reinforcement is not axissymmetrical to the column. This assumption is supported by experimental evidence (e.g. Kinnunen and Nylander, 1960; Regan, 1986). The assumption of axis-symmetrical behaviour is, on the contrary, dubious when the flexural reinforcement ratios in each orthogonal direction are considerably different (Figure 2). Figure 2(b) shows that the punching failure cone can be non-axissymmetrical in such cases.

The influence of the flexural reinforcement ratio $\rho$ on the punching shear strength is taken into account differently, depending on the design code applied. For example, ACI 318-08 neglects the influence of $\rho$ on the strength, whereas EC2 and BS 8110 assume that the strength is proportional to the factor 
$\left(100 \rho_{1}\right)^{1 / 3}$, where $\rho_{1}$ is an average reinforcement ratio obtained from $\rho_{x}$ and $\rho_{y}$. EC2 and BS 8110 limit $\rho_{1}$ to a maximum value of $2 \%$ and $3 \%$ respectively, whereas no restriction is given explicitly for the ratio $\rho_{x} / \rho_{y}$. This can be questionable since experimental data from tests with $\rho_{x} \neq \rho_{y}$ are limited. Design equations of the CSCT (Muttoni, 2008) adopt an axis-symmetrical model considering only the direction of the maximum slab rotation. In slabs with axis-symmetrical loading and $\rho_{x} \neq \rho_{y}$, this direction corresponds to the weakest reinforced direction. A series of punching shear tests with $\rho_{x} \geqslant \rho_{y}$ was carried out by the authors to investigate the assumptions in the design approaches mentioned above.

\section{Test specimens}

A total of seven punching shear tests (Figures 2 and 3) were carried out at École Polytechnique Fédérale de Lausanne (EPFL) on non-axis-symmetrical slabs without transverse reinforcement. The main variables investigated were the flexural reinforcement ratio in each direction and the type of loading (one-way and twoway spanning loading). The main characteristics of the specimens are summarised in Table 1 and Figure 3. The load was applied in the tests at eight or four points at equal distances from the centre of the slab, two on each side of the specimen (Figure 3(b)). Bending moments were balanced at the support. Two specimens were tested with symmetrical reinforcement and loading (control specimens PT22 and PT31). All specimens tested were $3 \mathrm{~m} \times 3 \mathrm{~m}$ and were $0.25 \mathrm{~m}$ thick. The slabs were supported on an internal square steel plate of side $c=260 \mathrm{~mm}$. The general dimensions and loading rig were similar to previous tests at EPFL with a symmetrical configuration (Guandalini et al., 2009). Further details of the loading rig and test procedure are given elsewhere (Tassinari et al., 2008).

Table 1 shows the values of the effective depth $d_{\text {avg }}$, which corresponds to the averaged distance measured from the bottom of the slab to the level of contact between reinforcement bars in $x$ and $y$ directions. The outer layer of reinforcement was oriented along the $y$ direction (north-south $(\mathrm{N}-\mathrm{S})$ ), which corresponds to the weak reinforced direction $\left(\rho_{y} \leqslant \rho_{x}\right)$. The flexural reinforcement ratio ranged from 1.64 to $0.32 \%$. The flexural capacity was assessed using the yield-line method with $d_{x}$ and $d_{y}$ measured from the bottom of the slab to the centre of the reinforcement bar. The reinforcement bars were equally spaced at 100,115 or $125 \mathrm{~mm}$ (Table 1). Flexural reinforcement in compression was provided at the bottom of the slab using $10 \mathrm{~mm}$ diameter bars equally spaced as for the tensile reinforcement.

\section{Material properties}

The measured values of concrete cylinder strength at the time of testing varied between 40 and 67.5 MPa (Table 1); the cylinders were $320 \mathrm{~mm}$ high and $160 \mathrm{~mm}$ in diameter. Table 2 shows the mix proportions of the concrete. Siliceous gravel from a gravel pit was used for the concrete with a maximum aggregate size $d_{\mathrm{g}}$ of $16 \mathrm{~mm}$. Experimental observations of the failure cone after testing (Figure 2(b)) showed that the cracks went round the

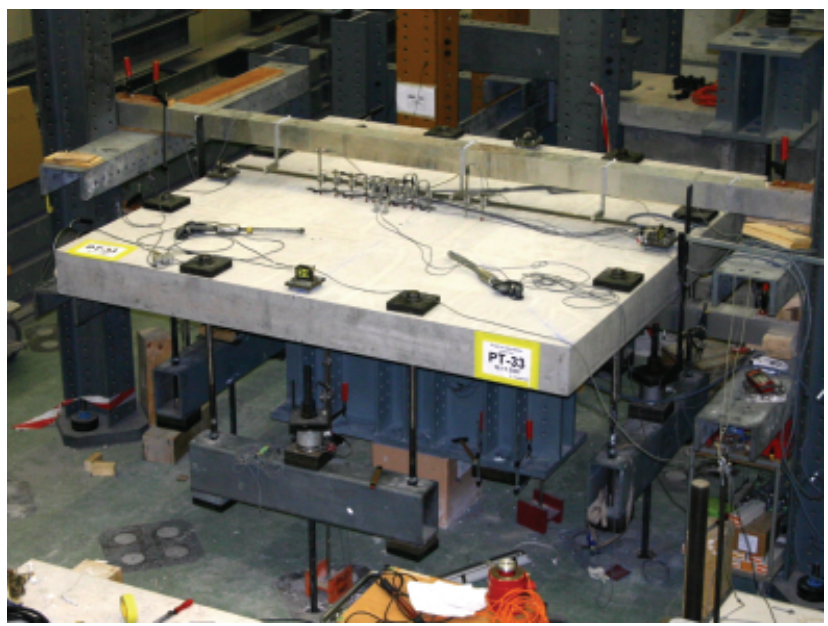

(a)

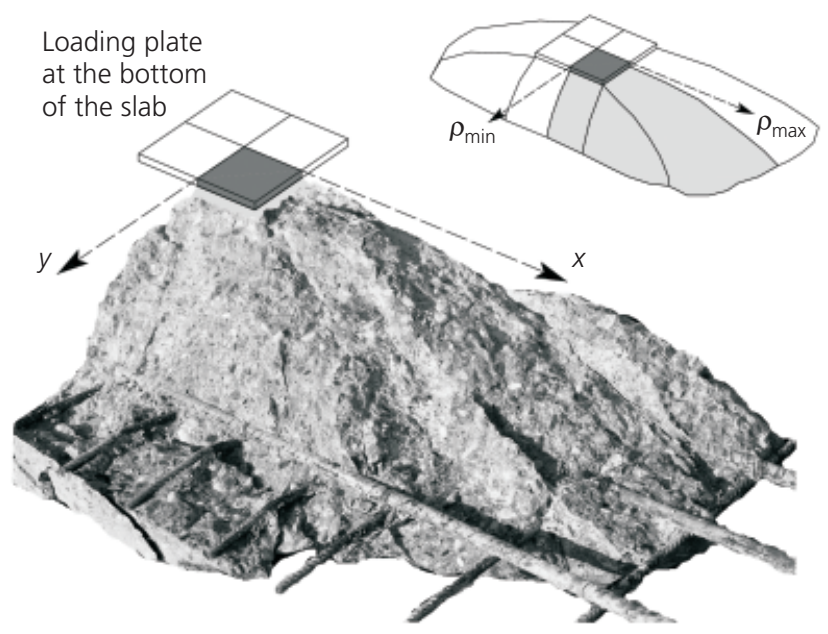

(b)

Figure 2. Punching shear tests at EPFL with non-symmetrical reinforcement ( $\rho_{\chi} / \rho_{y} \approx 0 \cdot 80 / 0 \cdot 35 \%$ ): (a) rig and loading arrangements (specimen PT33); (b) failure cone after testing (specimen PT23). (Note only one quadrant of the cone is shown; steep face corresponds to the weak reinforced direction)

aggregate (no aggregate fracture). The reinforcing steel used in the tests was hot-rolled for the reinforcement with nominal diameters 16 and $20 \mathrm{~mm}$ and cold-worked for the $10 \mathrm{~mm}$ diameter reinforcement. Table 1 shows the yield strength of the reinforcement obtained from tensile tests.

\section{Instrumentation and test set-up}

The specimens were highly instrumented (Tassinari et al., 2008). Slab rotations $\psi$ were measured along three directions ( $x, y$ and diagonal at $45^{\circ}$ ) using inclinometers as shown in Figure $3(\mathrm{c})$. The readings from the inclinometers correlated well with data from conventional transducers (LVDTs) placed at the top and bottom of the slab at several locations. Radial and tangential strains were measured from omega-shaped extensometers, with a measuring 


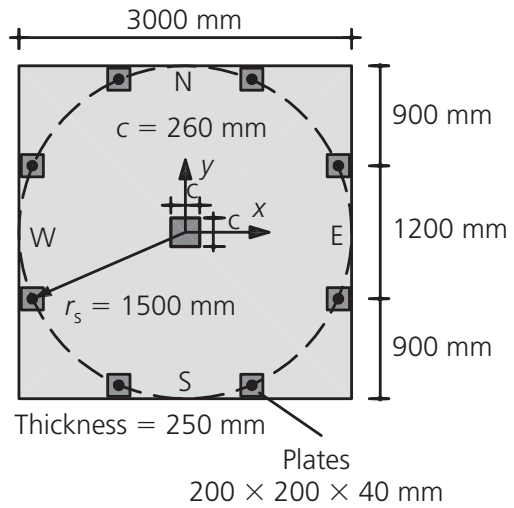

(a)

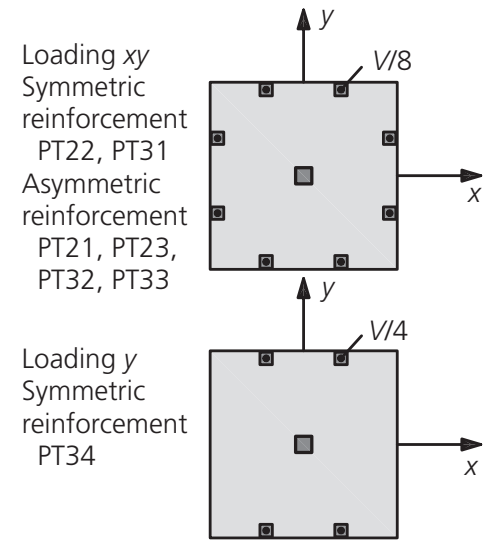

(b)

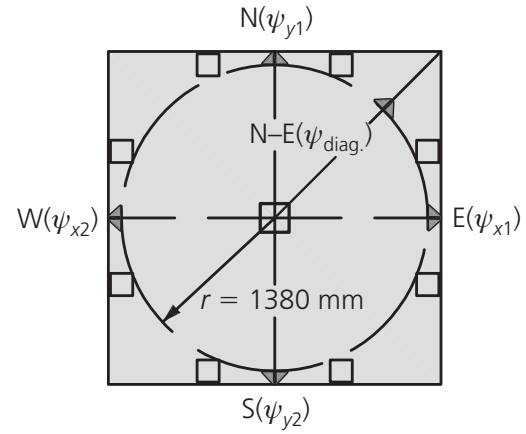

^ Inclinometer

(c)

Figure 3. Definition of test specimens: (a) general geometry;

(b) type of loading; (c) position of inclinometers for measuring slab rotations

\begin{tabular}{|c|c|c|c|c|c|c|c|c|}
\hline \multirow{2}{*}{$\begin{array}{l}\text { Test } \\
\text { specimen }\end{array}$} & \multirow[t]{2}{*}{ Loading } & \multirow[t]{2}{*}{ Reinforcement } & \multirow{2}{*}{$\begin{array}{l}d_{\text {avg: }}: \\
\mathrm{mm}\end{array}$} & \multirow{2}{*}{$\begin{array}{c}f_{\mathrm{c}}: \\
\mathrm{MPa}\end{array}$} & \multicolumn{4}{|c|}{ Flexural reinforcement (tensile) } \\
\hline & & & & & $\begin{array}{c}\text { Bar dia. } \\
(\text { dir. } x-y): \mathrm{mm}\end{array}$ & $\begin{array}{c}\rho_{x}-\rho_{y}: \\
\%^{*}\end{array}$ & $\begin{array}{l}f_{y x}: \\
\mathrm{MPa}\end{array}$ & $\begin{array}{l}f_{y y}: \\
\mathrm{MPa}\end{array}$ \\
\hline PT21 & Two-way & Asymmetric & 192 & $67 \cdot 5$ & $20-16$ & $1.64-0.84$ & 597 & 552 \\
\hline PT22 & Two-way & Symmetric & 196 & $67 \cdot 0$ & $16-16$ & $0.82-0.82$ & 552 & 552 \\
\hline PT23 & Two-way & Asymmetric & 189 & $66 \cdot 0$ & $16-10$ & $0.85-0.36$ & 552 & 568 \\
\hline РT31 & Two-way & Symmetric & 212 & $66 \cdot 3$ & $20-20$ & $1 \cdot 48-1.48$ & 540 & 540 \\
\hline PT32 & Two-way & Asymmetric & 215 & $40 \cdot 0$ & $20-16$ & $1.46-0.75$ & 540 & 558 \\
\hline РT33 & Two-way & Asymmetric & 212 & $40 \cdot 2$ & $16-10$ & $0.76-0.32$ & 558 & 533 \\
\hline PT34 & One-way & Symmetric & 216 & $47 \cdot 0$ & $16-16$ & $0.74-0.74$ & 558 & 558 \\
\hline
\end{tabular}

* Flexural reinforcement ratio $=A_{s} / s d_{\text {avg }}$ where $s$ is the bar spacing as follows: $100 \mathrm{~mm}$ (PT31, PT21x, PT32x); 115 mm (PT34, PT23y, PT33y);

$125 \mathrm{~mm}$ (PT22, PT23x, PT33x, PT21y, PT32y). Compression reinforcement: $10 \mathrm{~mm}$ bars with the same spacing as tensile reinforcement

Table 1. Summary of test specimens

$\begin{array}{ll}\text { Material } & \text { PT21, PT22, } \\ \text { PT23, PT31 } & \text { PT32, PT33, } 34\end{array}$

\begin{tabular}{lcc}
\hline Cement $\left(\right.$ Cem I): $\mathrm{kg} / \mathrm{m}^{3}$ & 300 & 325 \\
Plasticiser: $\mathrm{kg} / \mathrm{m}^{3}$ & $2 \cdot 38$ & - \\
Sand $(0-4 \mathrm{~mm}): \mathrm{kg} / \mathrm{m}^{3}$ & 1865 & 820 \\
Gravel $(4-8 \mathrm{~mm}): \mathrm{kg} / \mathrm{m}^{3}$ & 1105 & 432 \\
Gravel $(8-16 \mathrm{~mm}): \mathrm{kg} / \mathrm{m}^{3}$ & 820 & 621 \\
Water: $\mathrm{kg} / \mathrm{m}^{3}$ & 99 & 159 \\
Water/cement ratio & 0.33 & 0.49
\end{tabular}

Table 2. Concrete mixture proportions length of $100 \mathrm{~mm}$, which were placed near the $y$ axis at the bottom and top surfaces. The variation of slab thickness due to the development of diagonal shear cracks was also monitored (Tassinari et al., 2008).

\section{Test results}

All slabs tested failed in punching shear. The amount of flexural reinforcement had a significant influence on the type of failure and ultimate load. Specimens with reinforcement ratios $\rho_{x}$ and $\rho_{y}$ larger than $0.75 \%$ showed brittle failure (Figures 4(a), (c) and (d)) whereas tests with $\rho_{y}$ lower than $0.75 \%$ had sudden punching failure after large plastic deformations (Figures 4(b), (e) and (f)). This behaviour is in agreement with previous 


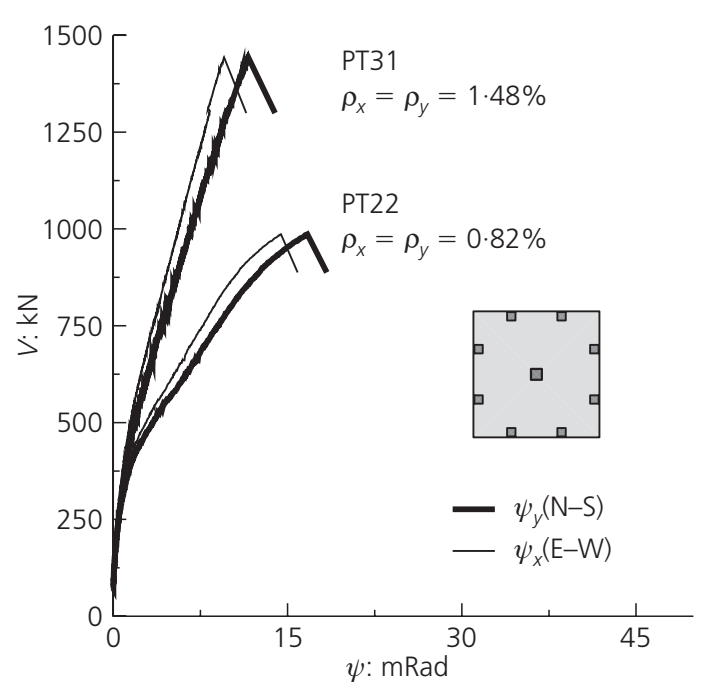

(a)

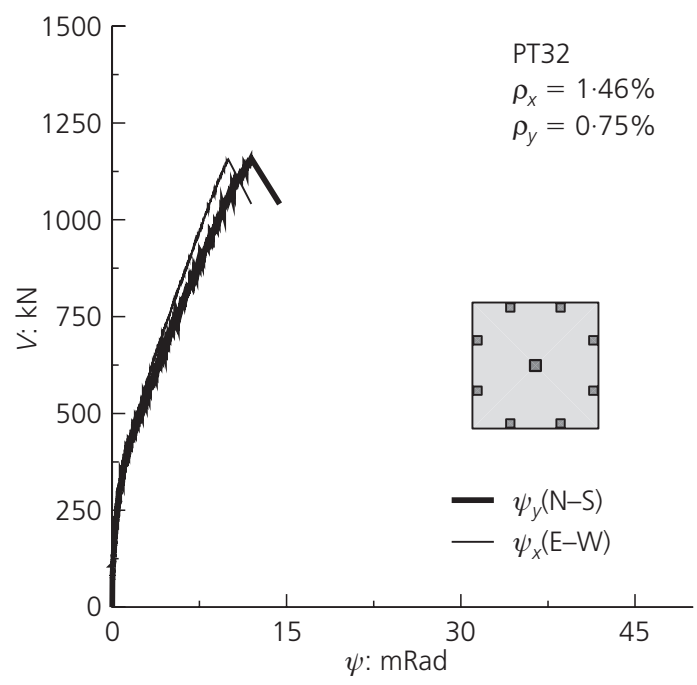

(c)

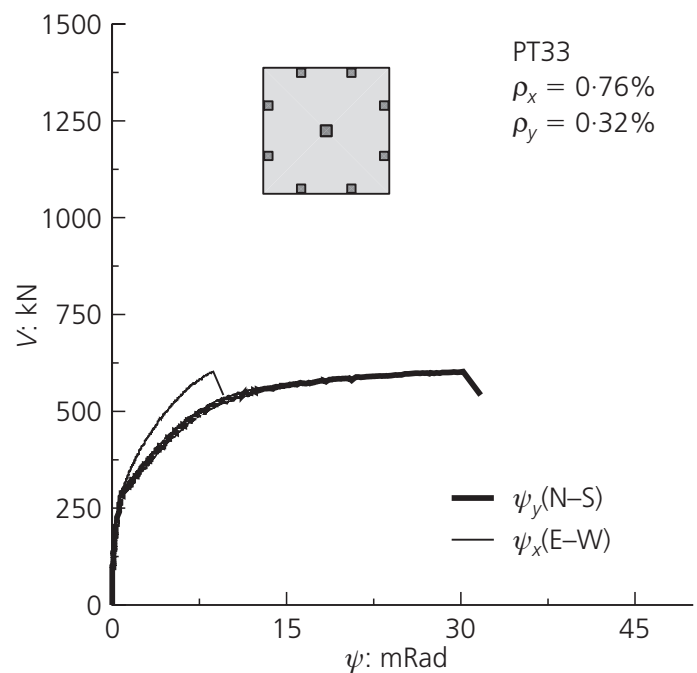

(e)

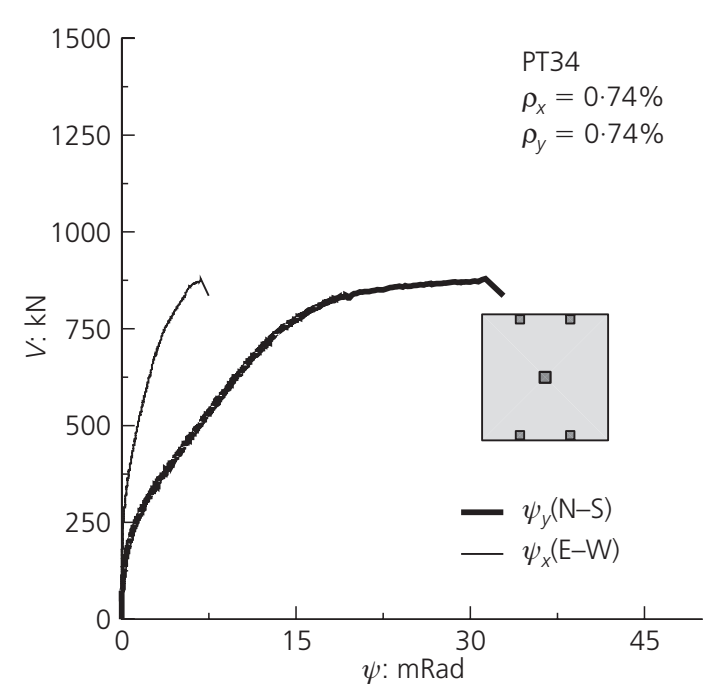

(b)

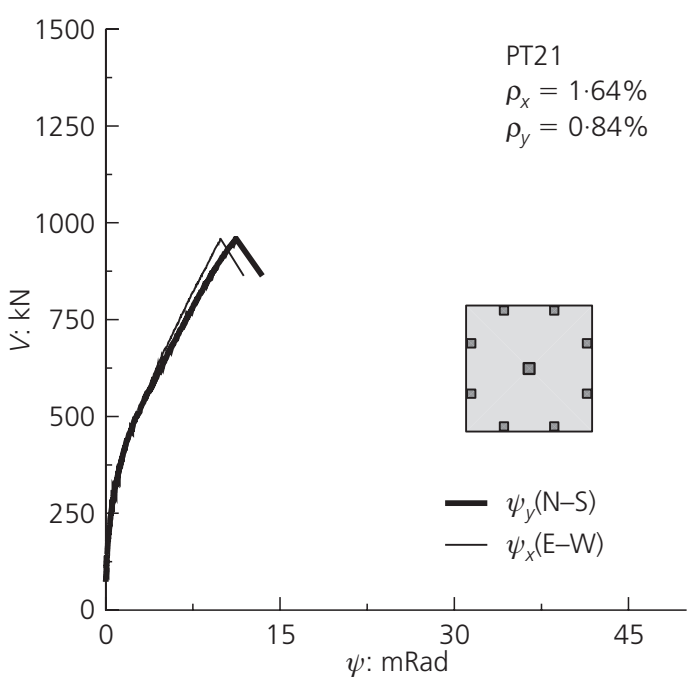

(d)

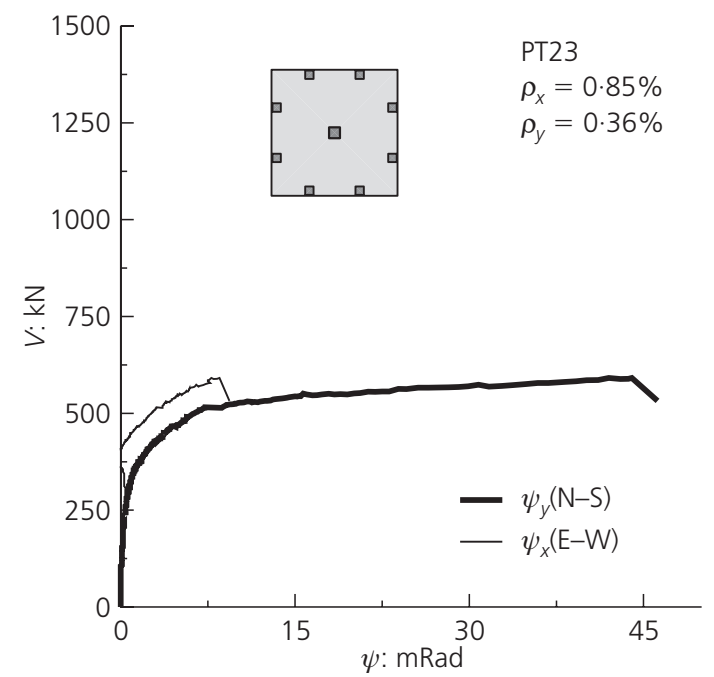

(f)

Figure 4. Measured slab rotations: (a) control specimens with symmetrical reinforcement and loading (PT22 and PT31); (b) symmetrical reinforcement and one-way spanning (PT34); (c), (d) asymmetrical reinforcement and symmetrical loading with $\rho_{x} / \rho_{y}=2$ and moderate $\rho_{y} ;(\mathrm{e})$ and (f) $\rho_{x} / \rho_{y}=2 \cdot 3$ and low $\rho_{y}$ 
findings from axis-symmetrical tests reported by Kinnunen and Nylander (1960) and Guandalini et al. (2009) among others. Muttoni and Schwartz (1991) noticed that punching shear strength reduces with lower flexural reinforcement ratios due to larger slabs rotations and wider crack openings, which is further supported in this work as shown in Figure 4. The radial strains measured at the bottom soffit near the column reduced considerably after the development of the critical shear crack, which was monitored during the tests. Several researchers, including Muttoni (2008), have reported a similar reduction of the radial strains in symmetrical tests.

As expected, the slab rotations in the $x-y$ directions of the control specimens PT22 and PT31 were similar (Figure 4(a)). This was not the case for PT34, which had similar reinforcement ratio in both directions as PT22 but was loaded with one-way spanning. Figure 4(b) shows that $\psi_{x}$ and $\psi_{y}$ in PT34 were significantly different from early load stages, even before the formation of the first flexural cracks. The difference between $\psi_{x}$ and $\psi_{y}$ was smaller in specimens PT23 and PT33 $\left(\rho_{x} \neq \rho_{y}\right)$ since they were loaded with two-way spanning. Near failure, $\psi_{x}$ and $\psi_{y}$ were, however, noticeably different as shown in Figures 4(e) and (f). The low value of $\rho_{y}(0 \cdot 3 \%)$ in PT23 and PT33 resulted in large rotations $\psi_{y}$. Interestingly, PT21 and PT32, which had a similar $\rho_{x} / \rho_{y}$ ratio but larger reinforcement ratios than PT23 and PT33, had a practically symmetrical response $\left(\psi_{x} \approx \psi_{y}\right)$ as shown in Figures $4(\mathrm{c})$ and (d).

Figure 5 shows the crack patterns of PT31, PT21, PT33 and PT34. It can be noted that the crack pattern is clearly non-axissymmetrical in all slabs except for the control specimen (PT31). Details for all specimens are described elsewhere (Tassinari et al., 2008). The specimens were cut into quarters after testing to examine the shear failure cone (Figures 2(b) and 5(e)). The slope of the cone was considerably steeper $\left(\sim 45^{\circ}\right)$ at the sides facing $\mathrm{N}-\mathrm{S}$, which corresponds to the maximum rotations, than at eastwest $(\mathrm{E}-\mathrm{W})\left(\sim 25^{\circ}\right)$ corresponding to the stiffer direction in bending. A similar trend was observed in symmetrical tests (Guandalini et al., 2009) in which the slope of the failure cone was generally steeper in slabs with the lowest reinforcement ratios. This experimental observation suggests that punching shear in slabs with $\rho_{x} \neq \rho_{y}$ can be treated considering the $x$ and $y$ directions individually as proposed in this paper.

\section{Strength predictions using design formulas}

The punching shear strength of the specimens tested was assessed using the design formulas in ACI 318-08 (ACI, 2008), EC2 (BSI, 2004) and BS 8110 (BSI, 1997), with partial material factors for concrete and steel equal to $1 \cdot 0$. These formulas are summarised below (in SI units of MPa and $\mathrm{mm}$ ).

ACI 318-08:

1. $V_{\mathrm{R}}=\frac{1}{3} \alpha b_{0} d\left(f_{\mathrm{c}}\right)^{1 / 2}$
EC2:

2. $V_{\mathrm{R}}=0 \cdot 18 b_{0} d\left[1+(200 / d)^{1 / 2}\right]\left(100 \rho_{1} f_{\mathrm{c}}\right)^{1 / 3}$

BS 8110:

3. $V_{\mathrm{R}}=0 \cdot 27 b_{0} d(400 / d)^{1 / 4}\left(100 \rho_{1} f_{\mathrm{cu}}\right)^{1 / 3}$

where $b_{0}$ is the control perimeter at a distance from the face of the column equal to $\lambda d$ ( $\lambda=2$ in EC2, $\lambda=1.5$ in BS 8110 and $\lambda=0.5$ in ACI $318-08$ and the CSCT). The control perimeter adopted in Equation 2 has round corners, whereas a simpler perimeter with straight sides is adopted in Equation 3. ACI 31808 allows use of a control perimeter with either straight or round corners; the latter option was adopted for consistency with CSCT approaches. Parameter $\alpha$ in Equation 1, which depends on the column size and shape, is equal to 1 for the specimens tested by the authors. Parameter $\rho_{1}$ is assessed in EC2 using a geometric average between $\rho_{x}$ and $\rho_{x}$ (i.e. $\rho_{1}^{2}=\rho_{x} \rho_{y}$ ), whereas an arithmetic average (i.e. $\left.\rho_{1}=\left(\rho_{x}+\rho_{y}\right) / 2\right)$ is generally applied in the UK following CP 110 (BSI, 1972) recommendations. Nevertheless, for ratios $\rho_{\max } / \rho_{\min }$ between 2 and 3 , the difference in the predicted strength is small $(<5 \%)$.

Figure 6 shows that the predictions using Equations 1-3 are reasonable, provided $V_{\mathrm{R}} \leqslant V_{\text {flex }}$. The EC2 formula provided the most accurate predictions, whereas the BS 8110 method gave slightly more conservative results. While simple, the ACI 318-08 formula seems highly inconsistent with test results, which showed a significant influence of the flexural reinforcement in the strength and symmetry of the response. Not surprisingly, Equation 1 provided the largest scatter in the predictions (Figure 6).

The predictions in Figures 6(a) and (b) show that adopting an averaged reinforcement ratio in Equations 2 and 3 provided accurate predictions. This supports the idea that each orthogonal direction $x-y$ contributes towards the overall punching strength. This is further supported by specimens PT32 and PT21 with $\rho_{x} / \rho_{y}=2\left(\rho_{1} \approx 1.0 \%\right.$ according to EC2) and symmetrical loading. The normalised strength of PT32 and PT21 was found to be identical to similar tests with $\rho_{x}=\rho_{y}=1 \cdot 0 \%$ from the literature (Hallgren, 1996; Papanikolaou et al., 2005; Regan, 1986). Although EC2 and BS 8110 formulas provide a good quantitative estimation of the strength, the approach is a very simplified representation of the problem. It remains unclear which is the real distribution of shear stresses along the perimeter and what is the contribution of each orthogonal direction towards the total strength. These uncertainties can be particularly relevant in strongly non-symmetrical cases. This paper now presents a model based on the CSCT that considers slab rotations in the $x$ and $y$ directions $\left(\psi_{x}\right.$ and $\left.\psi_{y}\right)$. The proposed approach gives predictions as accurate as those from the EC2 formula and provides a 
Magazine of Concrete Research

Volume 63 Issue 6
Non-axis-symmetrical punching shear around internal columns of RC slabs

without transverse reinforcement

Sagaseta, Muttoni, Fernández Ruiz and

Tassinari

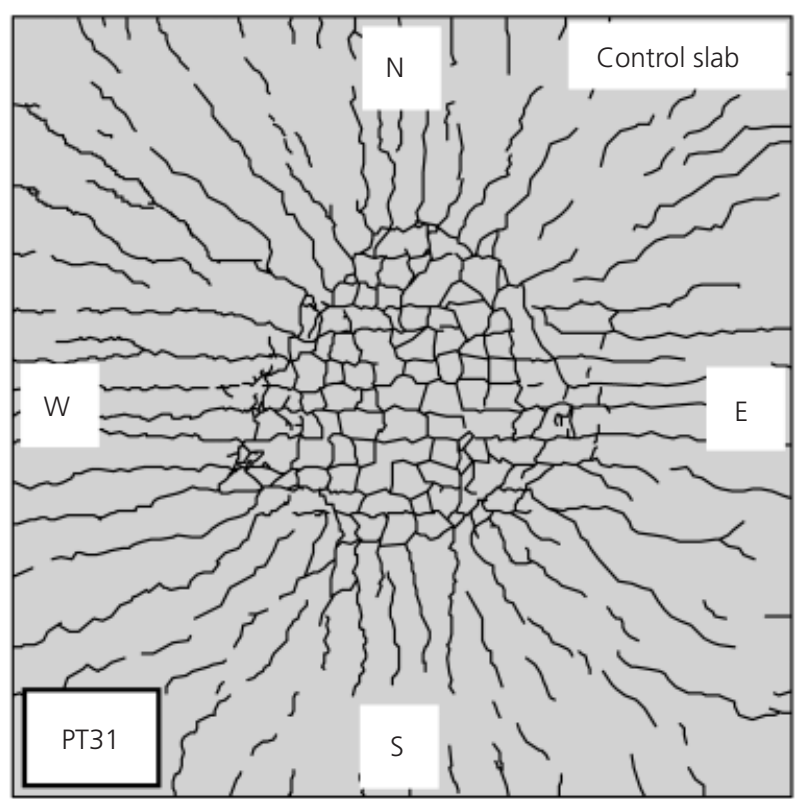

(a)

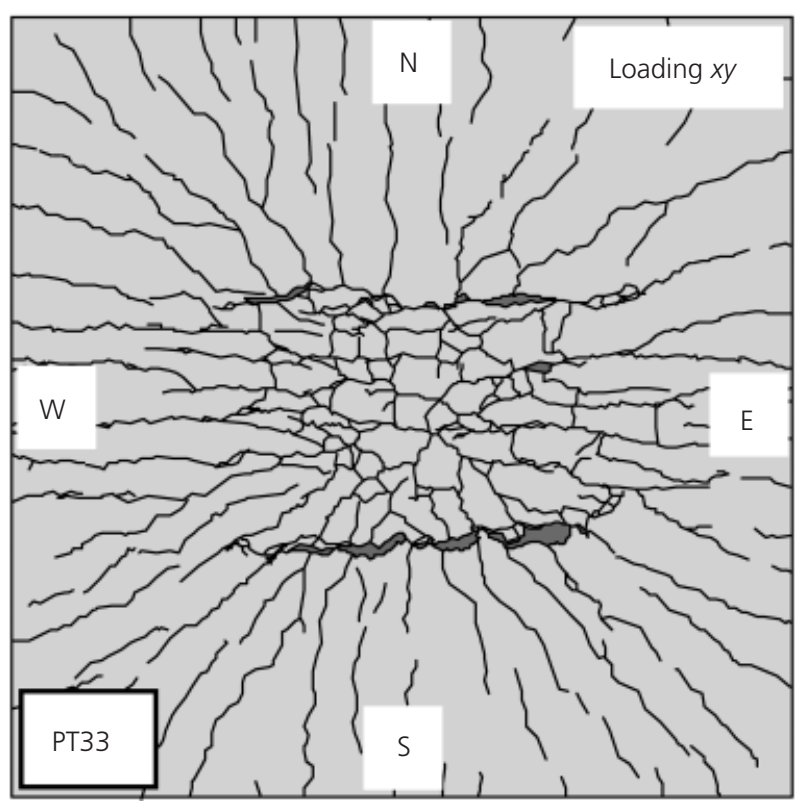

(c)

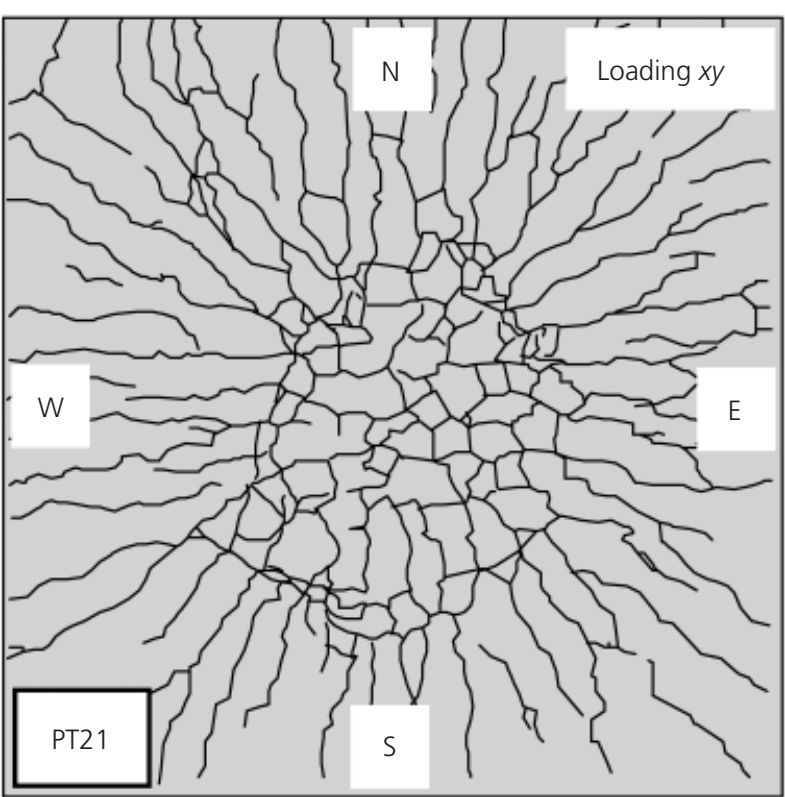

(b)

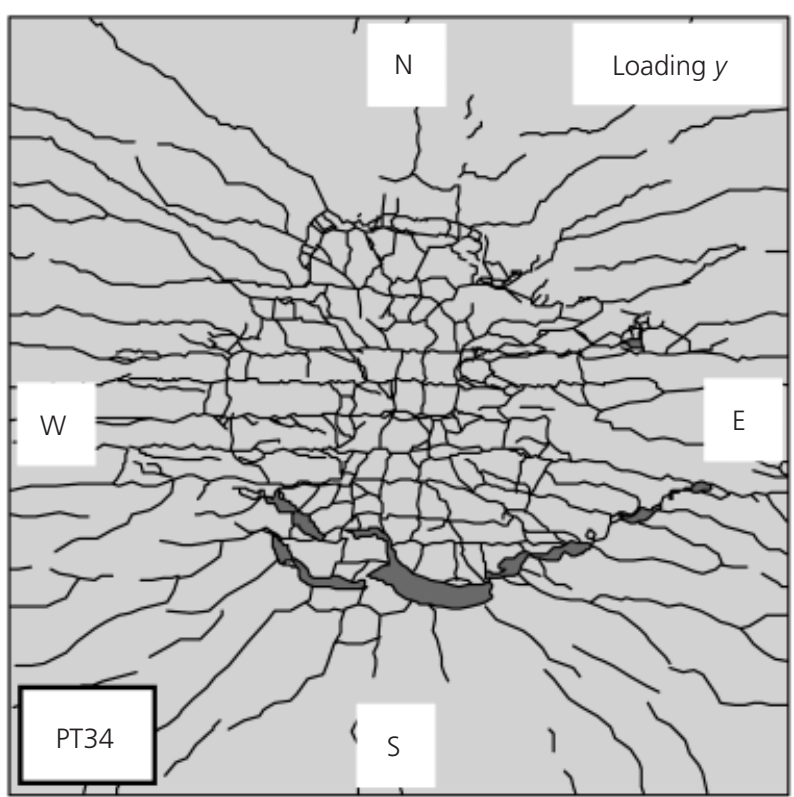

(d)

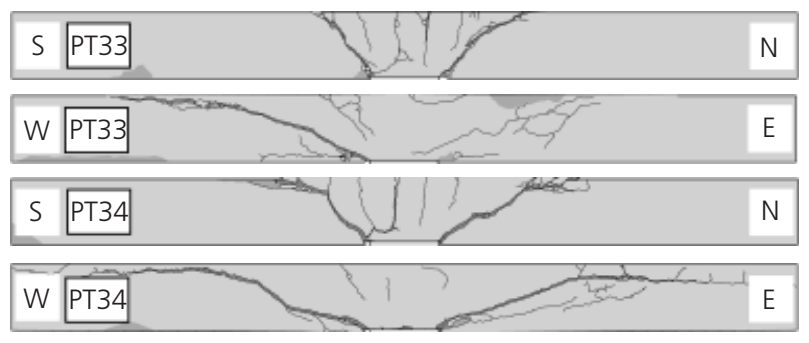

(e)

Figure 5. Crack pattern after failure in punching shear tests: (a), (b) tests with axis-symmetrical response (PT31 and PT21); (c), (d) tests with non-symmetrical response (PT33 and PT34); ;(e) transverse sections along $x$ and $y$ axis of specimens PT33 and PT34. (Note specimens PT22, PT23 and PT32 had a similar crack pattern to PT31, PT33 and PT21 respectively) 


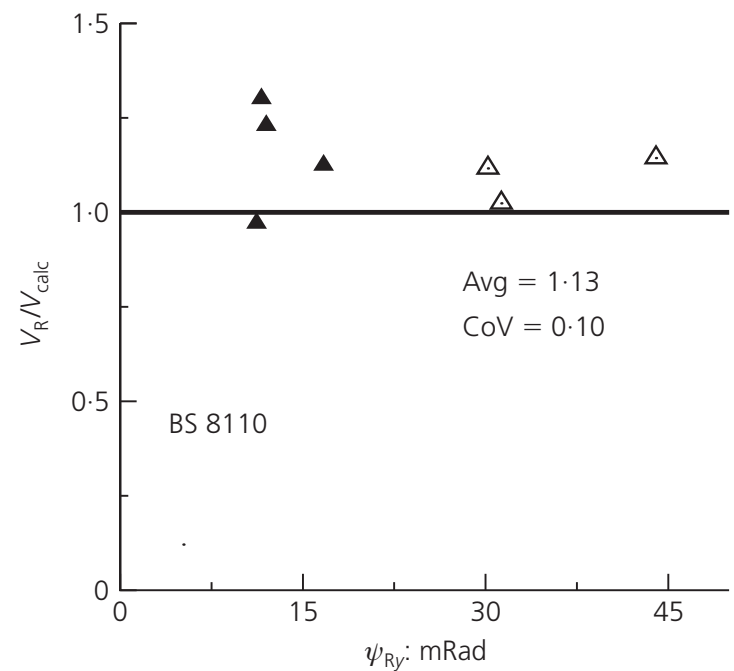

(a)

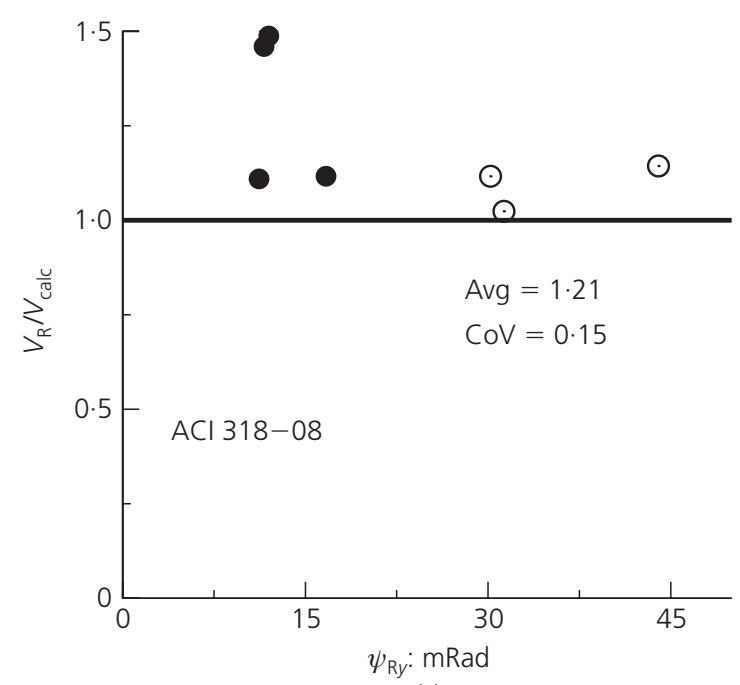

(c)

Figure 6. Comparison between predictions of punching shear strength of slabs tested according to different design codes: (a) BS 8110 (BSI, 1997); (b) EC2 (BSI, 2004); (c) ACI 318-08 $(\mathrm{ACl}, 2008)$

physical explanation behind averaging the strengths corresponding to the $x$ and $y$ directions.

\section{Analysis using the critical shear crack theory}

The punching shear strength and slab rotation at failure can be estimated using the CSCT as presented by Muttoni (2008) and Muttoni and Fernández Ruiz (2008). According to the CSCT, punching failure is governed by the presence of a critical shear crack developing through the theoretical strut (Muttoni and Schwartz, 1991), as shown in Figure 7(a). Failure occurs due to the loss of aggregate interlock action along the critical shear

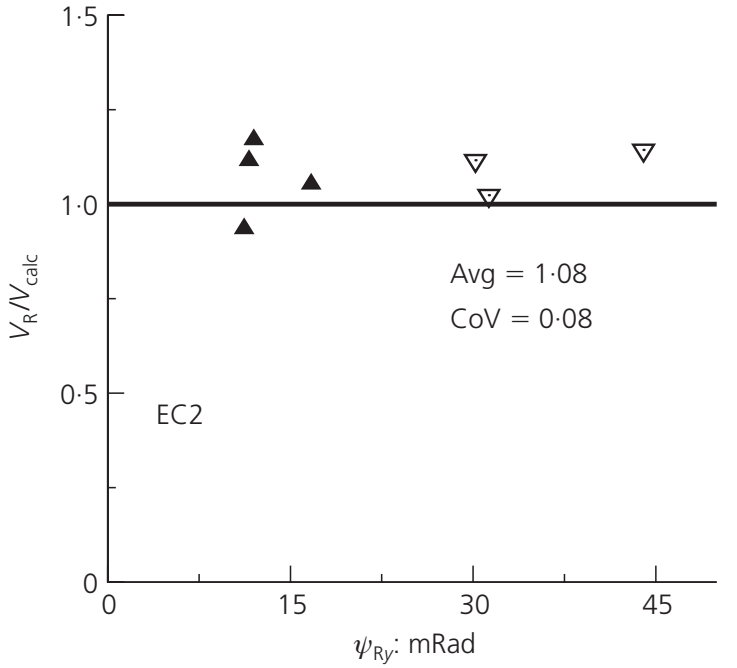

(b)

\section{- Shear governing \\ $\triangle$ Flexure governing \\ $\nabla$ Flexure governing \\ - Shear governing \\ Flexure governing}

crack, which is governed primarily by the crack opening $(w)$ and the crack roughness. The punching shear strength decreases with increasing slab rotations since the opening of the critical shear crack increases (Muttoni and Schwartz, 1991). This explains the reduction in punching shear strength observed experimentally in slabs with lower reinforcement ratios.

Muttoni (2008) proposed the failure criterion given by Equation 4, which assumes that the width of the critical crack is proportional to the slab rotation multiplied by the effective depth of the member $(w \propto \psi d)$ as shown in Figure 7(a). Equation 4 also considers the 


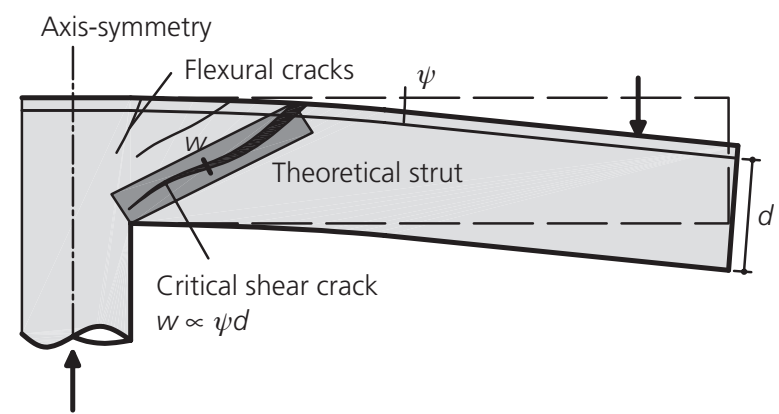

(a)

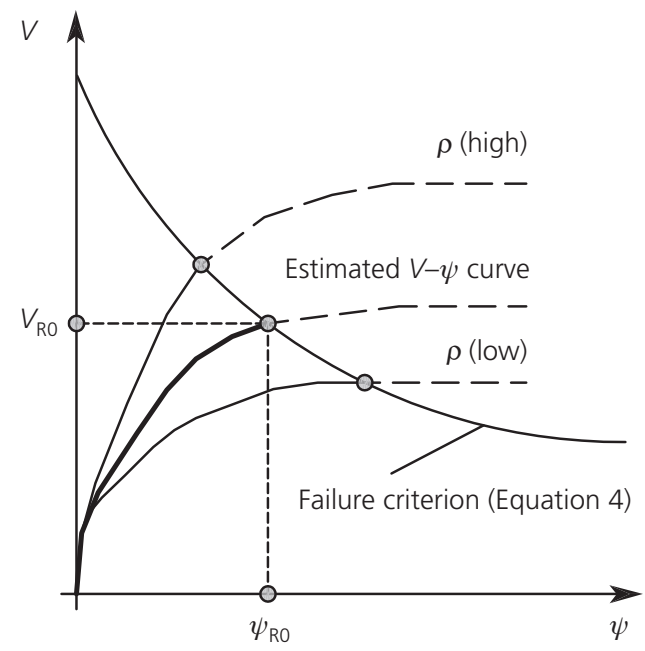

(c)

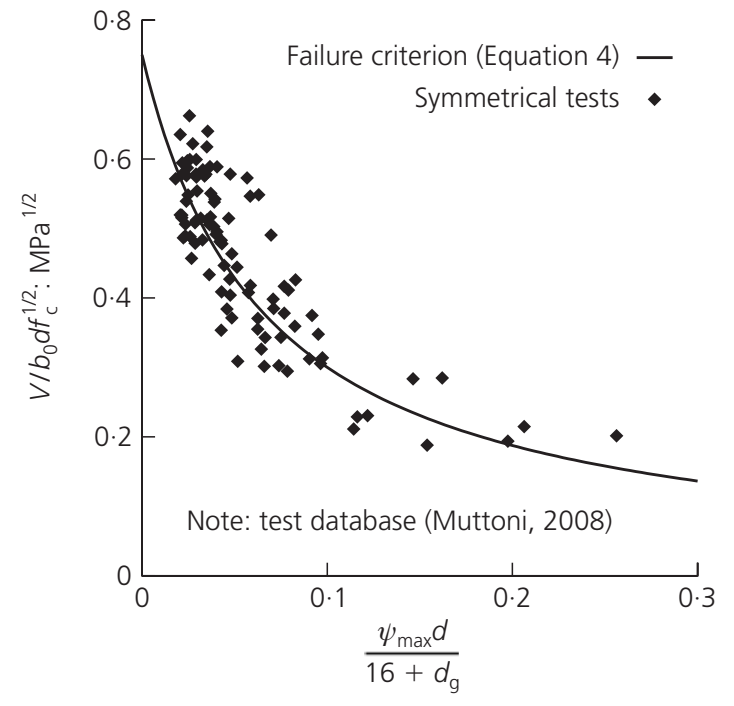

(b)

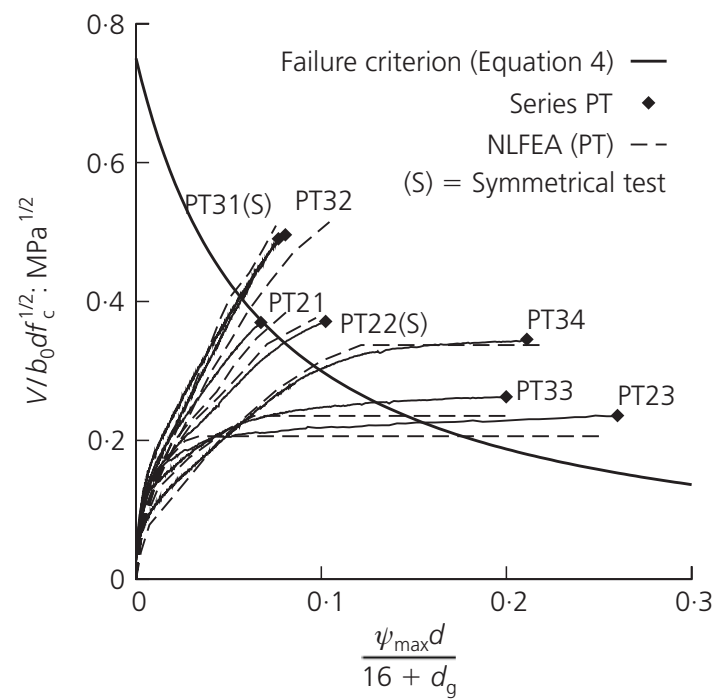

(d)

Figure 7. Punching shear analysis according to the CSCT:

(a) punching failure due to critical shear crack crossing theoretical strut (Muttoni, 2008); (b) failure criterion and experimental data from symmetrical tests (database from Muttoni (2008));

(c) assessment of ultimate failure load and slab rotation at failure;

(d) experimental versus predicted (NLFEA) load-rotation

relationships

influence of concrete strength and crack roughness, which is given in terms of the maximum aggregate size $d_{\mathrm{g}}$.

$$
\text { 4. } \frac{V_{\mathrm{R}}}{b_{0} d\left(f_{\mathrm{c}}\right)^{1 / 2}}=\frac{3 / 4}{1+15\left[\psi d /\left(d_{\mathrm{g}, 0}+d_{\mathrm{g}}\right)\right]}
$$

where $d_{\mathrm{g}, 0}$ is taken as $16 \mathrm{~mm}, b_{0}$ is the control perimeter with round corners at a distance of $0 \cdot 5 d$ from the face of the column, $d$ is the average flexural depth of the slab and $\psi$ is the slab rotation for axis-symmetrical cases. The slab rotation is assumed to be constant outside the perimeter delimited by the critical shear crack (i.e. the slab deforms following a conical shape). The nominal strength $v_{\mathrm{R}}$ is obtained by multiplying both sides of Equation 4 by $d\left(f_{\mathrm{c}}\right)^{1 / 2}$. Figure $7(\mathrm{~b})$ shows that Equation 4 performs well for symmetrical tests (Muttoni, 2008).

An additional advantage of this approach is that the deformation 
capacity (slab rotation at failure) can also be predicted. In order to do so, the load-rotation relationship of the slab must be estimated by carrying out a refined non-linear finite-element analysis (NLFEA) or using simplified formulas such as Equation 5, which was proposed by Muttoni (2008)

5. $\psi=1 \cdot 5 \frac{r_{\mathrm{s}}}{d} \frac{f_{\mathrm{y}}}{E_{\mathrm{s}}}\left(\frac{V}{V_{\text {flex }}}\right)^{3 / 2}$

where $V_{\text {flex }}$ is the flexural strength and $r_{\mathrm{s}}$ is the radius of the isolated slab element considered; $r_{\mathrm{s}}$ was taken as $1.5 \mathrm{~m}$ (halfwidth of the members) for the slabs tested. The intersection between the estimated load-rotation curve and the failure criterion (Equation 4) shown in Figure 7(c) corresponds to the predicted ultimate failure load and rotation $\left(V_{\mathrm{R} 0}\right.$ and $\psi_{\mathrm{R} 0}$ respectively). Equation 4 might intersect the load-rotation curve at its plateau, corresponding to the flexural capacity of the slab $\left(V=V_{\text {flex }}\right)$. This is the case for slabs with a low level of flexural reinforcement $\rho$ such as in specimens PT23 and PT33 shown in Figure $7(d)$ in which punching failure occurred after large plastic deformations and yielding of the entire reinforcement bars.

\section{Considerations for non-axis-symmetrical punching in the} CSCT

Equation 4 considers the governing crack width. In practice, the analysis of non-axis-symmetrical punching using the CSCT is carried out using $\psi_{\max }$, which is assessed along the direction with maximum rotations. The nominal strength $v_{\mathrm{Rmax}}$ is thus assessed by substituting $\psi_{\max }$ into Equation 4. The total strength is estimated as the integral of $v_{\mathrm{Rmax}}$ along the control perimeter assuming a constant value (i.e. $V_{\mathrm{R} 0}=b_{0} v_{\mathrm{Rmax}}$ ). Whilst conservative (as larger rotations lead to lower strengths), the $\operatorname{CSCT}\left(\psi_{\max }\right)$ approach is practical for design purposes and generally provides reasonable predictions (Muttoni, 2008; Sagaseta et al., 2009). This method is currently implemented in Swiss code SIA 262 (SIA, 2003).

A comparison of the $\operatorname{CSCT}\left(\psi_{\max }\right)$ predictions to the tests results on the PT specimens was performed by the authors; the results from this analysis are described elsewhere (Sagaseta et al., 2009). The load-rotation relationship in the slabs tested was estimated using NLFEA, which accounted for plastic redistributions due to bending but not due to shear deformations. Shell elements with a quadrilinear moment-curvature relationship (Muttoni, 2008) were adopted. The torsional stiffness of the elements was reduced by a constant factor of $1 / 8$ to account for cracking (Vaz Rodrigues, 2007). Figure 7(d) shows that the load-rotation relationships were predicted accurately by the NLFEA.

Figure 8(a) shows the predicted shear stress field from the NLFEA for specimen PT34 (one-way slab) in which contact elements were adopted to model the column-slab interface more accurately. The shear stress vector fields in Figure 8 are represented using flow lines that follow the principal directions with a line thickness

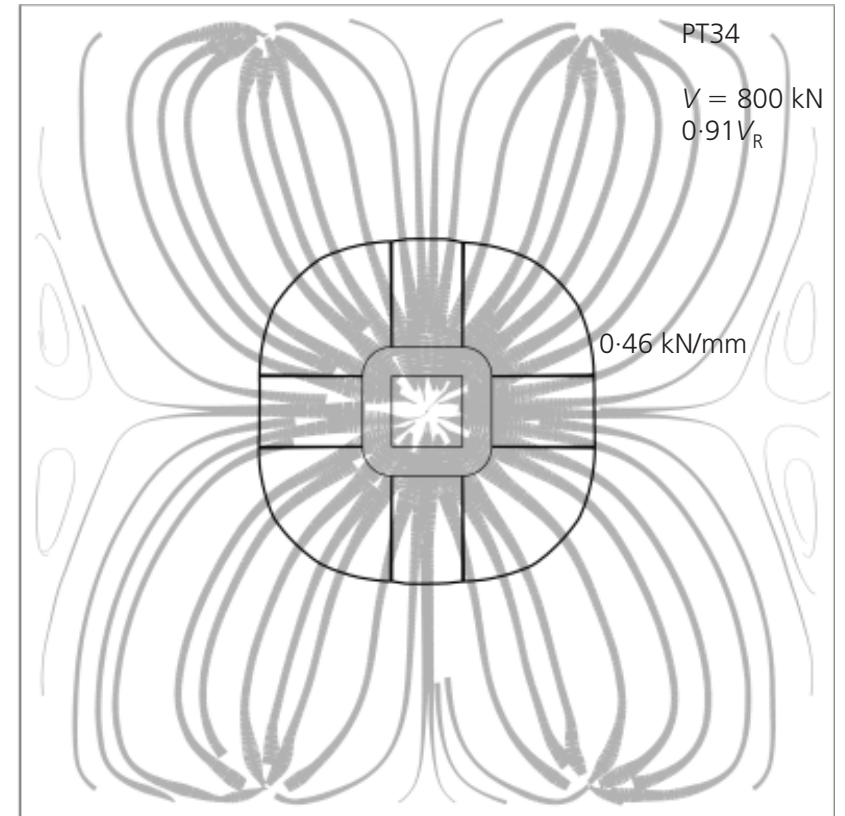

(a)

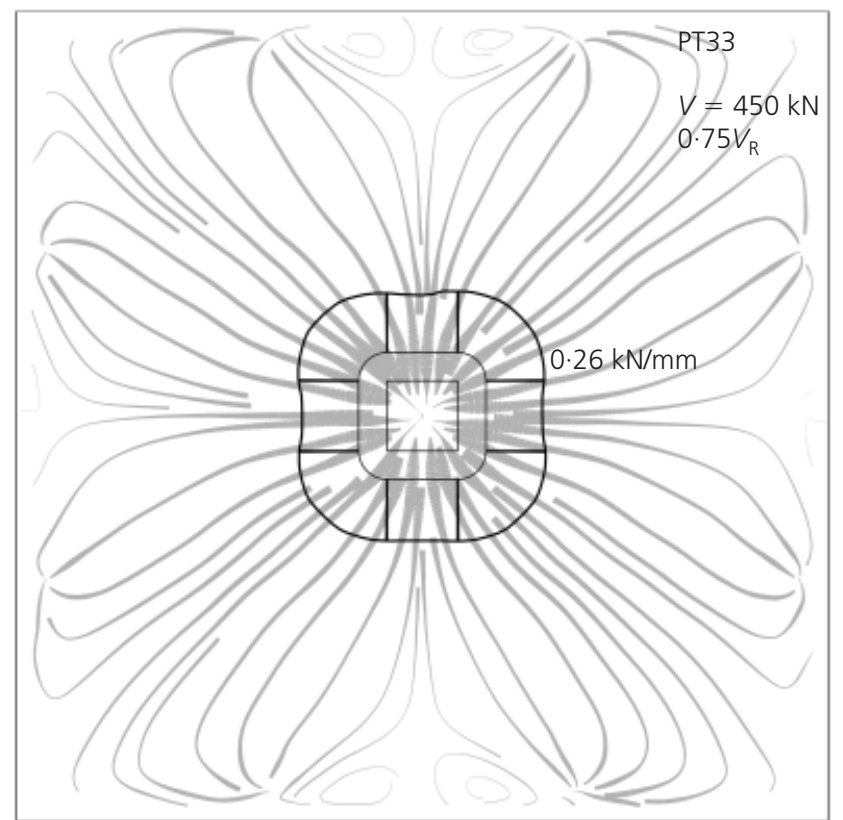

(b)

Figure 8. Shear stress field and distribution of shear stresses along control perimeter at $d / 2$ from the column face, obtained from NLFEA: (a) PT34 with one-way spanning and $\rho_{x}=\rho_{y}$; (b) PT33 with two-way spanning and $\rho_{x} / \rho_{y}=2 \cdot 3$

proportional to the magnitude of the shear force per unit length (Vaz Rodrigues et al., 2008). The results indicated that although the load and slab deformations were non-axis-symmetrical, the shear stresses around the control perimeter were roughly constant for loads below punching failure. Similar results were also obtained for the two-way loading tests (Figure 8(b)). 
The average $V_{\mathrm{R}} / V_{\text {calc }}$ ratio for PT specimens according to the $\operatorname{CSCT}\left(\psi_{\max }\right)$ approach using a refined estimation of the loadrotation curves was $1 \cdot 12$ (Sagaseta et al., 2009). Figure 7(d) shows that the deformation capacity in tests with $\psi_{y}>\psi_{x}$ (PT23, PT33 and PT34) was underestimated. This difference was largest in PT34 where $\psi_{y} \gg \psi_{x}$. This was somewhat expected since the $\operatorname{CSCT}\left(\psi_{\max }\right)$ method considers only the weakest reinforced direction. The next section shows that more reasonable predictions are obtained using the CSCT considering a nonuniform distribution of $\psi$ around the control perimeter; this method also provides a better understanding of the shear force distribution.

\section{Proposed approach based on the CSCT with shear stress redistribution}

According to the CSCT, the nominal punching strength $v_{\mathrm{R}}(s)$ in non-axis-symmetrical slabs is non-uniform along the control perimeter since the slab rotation $\psi(s)$ depends on the direction considered (Figure 9(a)). This means that some parts of the perimeter will reach their ultimate strength, whereas others will still have a potential strength capacity. This additional strength is neglected in practice since a constant nominal strength $v_{\text {Rmax }}$ around the perimeter is assumed (Figure 9(b)). In reality, once the nominal shear stresses reach the nominal strength $v_{\text {Rmax }}$, a softening of shear will occur at segments with the largest slab rotations (segment A in Figure 10). This softening of shear strength, which can be assumed to follow the failure criterion given by Equation 4, is accompanied by an increase of shear at segments of the perimeter with higher nominal strength (segment $\mathrm{B}$ in Figure 10). The redistribution of shear stresses from $\mathrm{A}$ to $\mathrm{B}$ (Figure 10) results in higher punching shear strengths and slab rotations than the initially estimated values of $V_{\mathrm{R} 0}$ and $\psi_{\mathrm{R} 0}$. This is true provided that the increase in shear at B shown in Figure 10 balances the softening in shear at A.

The punching strength can be determined in a general case by integrating the nominal strength along the control perimeter (Equations 6 and 7, which are based on the same principles as Equation 4 for axis-symmetrical cases)

$$
\text { 6. } \quad V_{\mathrm{R}}=\oint_{\mathrm{cp}} \nu_{\mathrm{R}}(s) \mathrm{d} s
$$

where

$$
\text { 7. } \quad v_{\mathrm{R}}(s)=\frac{(3 / 4) d\left(f_{\mathrm{c}}\right)^{1 / 2}}{1+15\left[\psi(s) d /\left(d_{\mathrm{g}}+d_{\mathrm{g}, 0}\right)\right]}
$$

Equations 6 and 7 can be applied in a general manner to different column geometries assuming different relationships for the slab rotations $\psi(s)$ along the control perimeter. The assumed relationship $\psi(s)$ should be validated experimentally, although predictions

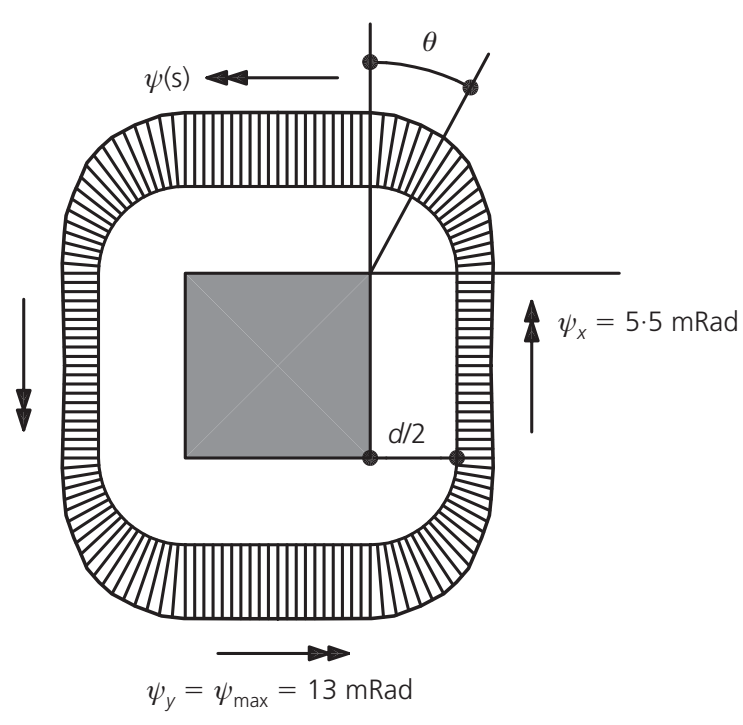

(a)

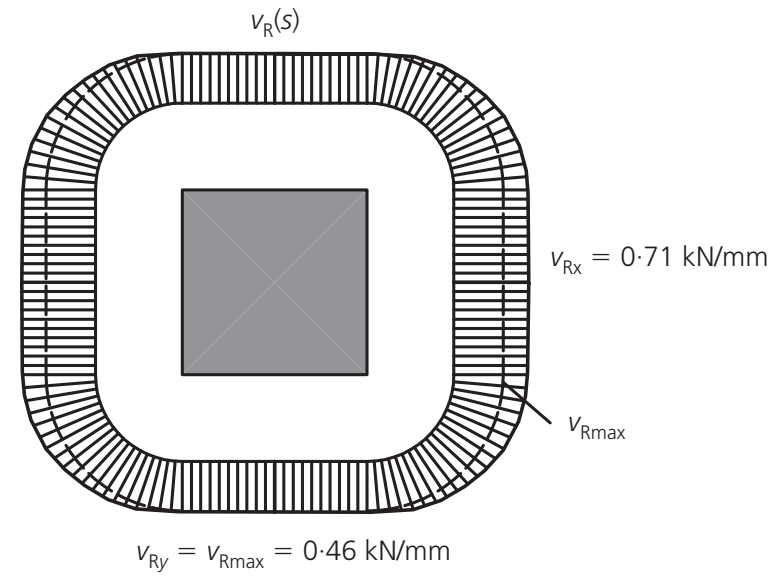

(b)

Figure 9. Non-uniform distribution along the control perimeter of (a) slab rotations (NLFEA predictions for PT34 at $800 \mathrm{kN}$ ) and (b) corresponding nominal strengths according to the CSCT (Equation 4)

from FEA or similar approaches can provide useful information. The rotations $\psi(s)$ can be assumed to be constant along the straight segments of the control perimeter in slabs supported on square columns such as specimens PT. The transition between $\psi_{y}$ and $\psi_{x}$ is assumed to take place at the corners primarily, leading to

$$
\text { 8. } \quad V_{\mathrm{R}}=\oint_{\mathrm{cp}} \nu_{\mathrm{R}}(s) \mathrm{d} s=2 c\left(\nu_{\mathrm{R} x}+v_{\mathrm{R} y}\right)+V_{\mathrm{R}, \text { corners }}
$$

in which 


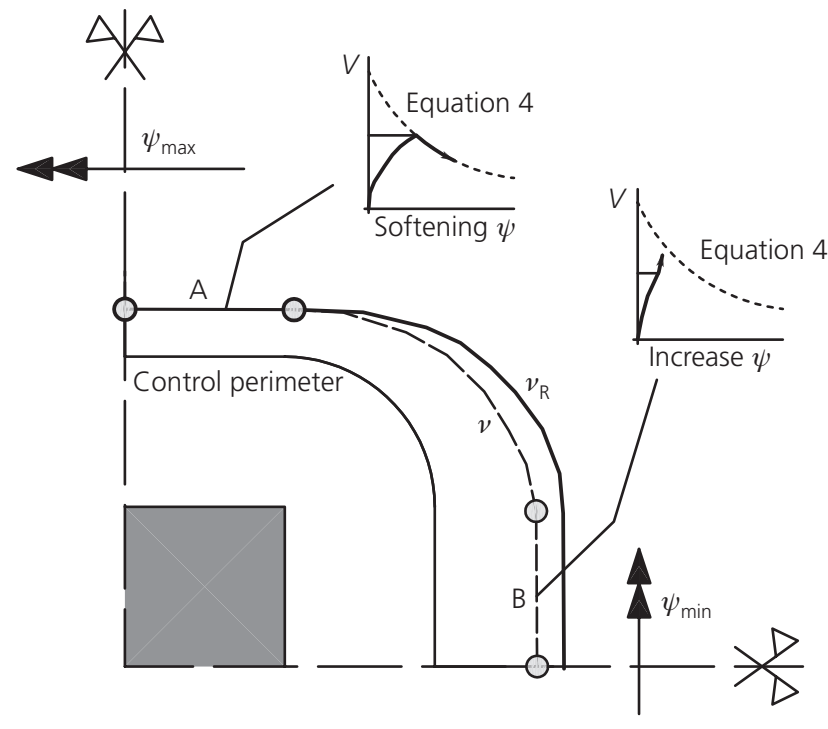

Figure 10. Shear stress redistribution from segments of the control perimeter with largest slab rotations (shear softening) to segments with lowest slab rotations (increase in shear)

9a. $\quad v_{\mathrm{R} x}=\frac{(3 / 4) d\left(f_{\mathrm{c}}\right)^{1 / 2}}{1+15\left[\psi_{x} d /\left(d_{\mathrm{g}}+d_{\mathrm{g}, 0}\right)\right]}$

9b. $\quad v_{\mathrm{R} y}=\frac{(3 / 4) d\left(f_{\mathrm{c}}\right)^{1 / 2}}{1+15\left[\psi_{y} d /\left(d_{\mathrm{g}}+d_{\mathrm{g}, 0}\right)\right]}$

10. $V_{\mathrm{R}, \text { corners }}=4 \int_{0}^{\pi / 2} \nu_{\mathrm{R}}(\theta) \frac{d}{2} \mathrm{~d} \theta$

where $V_{\mathrm{R}, \text { corners }}$ is the total strength corresponding to the four corners. The angle $\theta$ varies between 0 and $\pi / 2$ (Figure 9(a)) and $\nu_{\mathrm{R}}(\theta)$ is the nominal strength corresponding to the rotation $\psi(\theta)$ according to Equation 7. Figure 11(a) shows the readings from the $x, y$ and diagonal inclinometers in specimen PT23 with low $\rho_{y}$. These readings indicate that the relationship $\psi(\theta)$ was approximately parabolic for loads near failure. Figure 11(b) shows the corresponding nominal strength to the slab rotations according to Equation 7. The predicted strength at the corner $\left(V_{\mathrm{R}, \text { corners }} / 4\right)$ is proportional to the area below the $\nu_{\mathrm{R}}-\theta$ curves shown in Figure 11(b) by a factor of $d / 2$, which corresponds to the radius of the control perimeter at the corner applied in Equation 10.

Equation 6 was implemented in a post-processing routine in a finite-element software package (Ansys) in order to gain better insight into $\psi(s)$. This analysis was carried out for the PT specimens using the deflections previously estimated in the

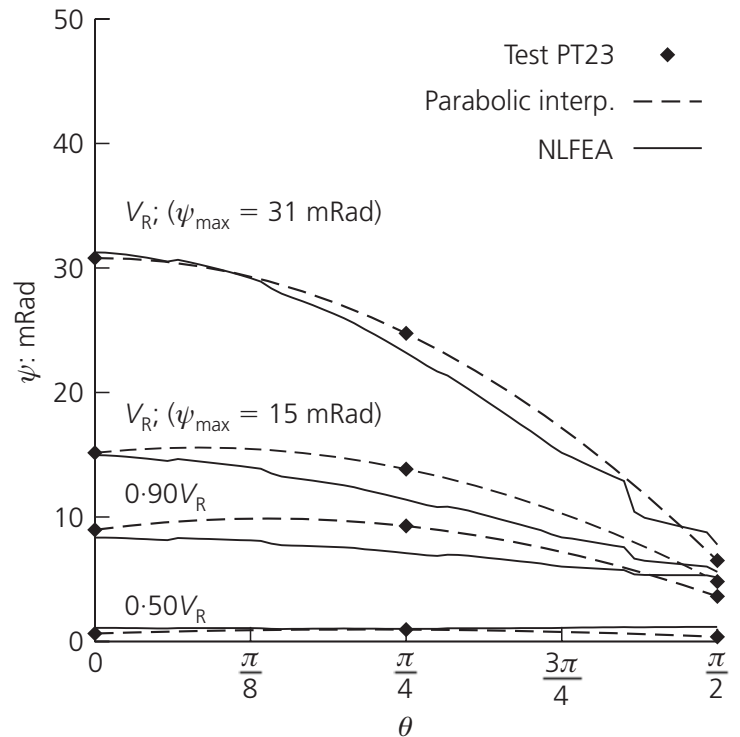

(a)

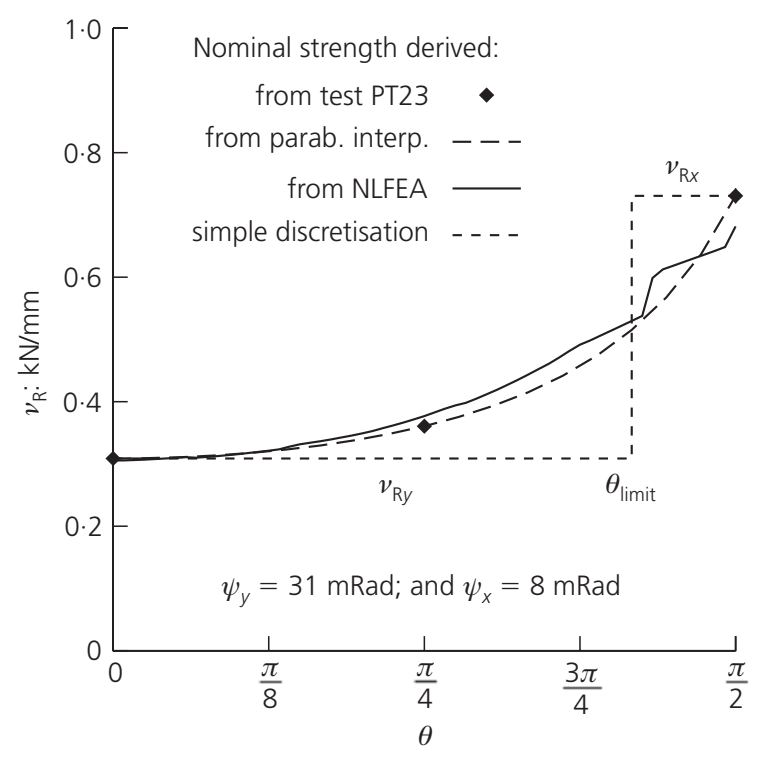

(b)

Figure 11. Transition of slab rotation and nominal strength along the corner of the control perimeter $(\theta=0-\pi / 2)$ in specimen PT23: comparison between (a) measured and predicted slab rotation and (b) corresponding nominal strength according to the CSCT (Equation 4)

NLFEA. The control perimeter was subdivided into 160 segments as shown in Figure 9. The rotation $\psi_{i}$ and nominal strength $v_{\mathrm{R} i}$ were assessed for each segment. Figures 9 and 11 show the results for PT34 and PT23 respectively. This refined analysis showed that:

(a) the rotations were fairly constant along the straight sides of the perimeter, as assumed 
(b) the rotations $\psi(\theta)$ at the corners followed an approximately parabolic relationship, which is consistent with experimental evidence.

Further experimental and analytical work is required for columns with different shapes and size ratios to those presented here.

\section{Simplified discretisation of the control perimeter into $x-y$ segments}

The general approach described can be simplified significantly by dividing the control perimeter into four segments - two segments for each orthogonal direction, as shown in Figure 12. This method is referred to as $\operatorname{CSCT}\left(\psi_{x}-\psi_{y}\right)$. The slab rotations $\psi_{x}$ $\psi_{y}$ and nominal strengths $\nu_{\mathrm{R} x}-v_{\mathrm{R} y}$ are assumed to be constant along $b_{x}-b_{y}$, leading to:

11. $V_{\mathrm{R}}=\nu_{\mathrm{R} x} b_{x}+\boldsymbol{v}_{\mathrm{R} y} b_{y}=\frac{V_{\mathrm{R} x}}{b_{0}} b_{x}+\frac{V_{\mathrm{R} y}}{b_{0}} b_{y}$

where $V_{\mathrm{R} x}$ and $V_{\mathrm{R} y}$ are the strengths calculated using Equation 4 with $\psi_{x}$ and $\psi_{y}$ respectively and $b_{0}=b_{x}+b_{y}$. A similar discretisation of the perimeter is proposed by the Concrete Society (2005) to estimate the strength of post-tensioned concrete slabs. It is interesting to note that if $V_{\mathrm{R} x}$ and $V_{\mathrm{R} y}$ in Equation 11 are estimated using the EC2 formula (BSI, 2004) with $\rho_{x}$ and $\rho_{y}$ respectively and $b_{x}=b_{y}=b_{0} / 2$, an average reinforcement ratio of $\rho_{1}=\left[\left(\rho_{x}^{(1 / 3)}+\rho_{y}^{(1 / 3)}\right) / 2\right]^{3}$ is obtained. This cubic expression for $\rho_{1}$ gives very similar values to that adopted in EC2: $\rho_{1}=\left(\rho_{x} \rho_{y}\right)^{0.5}$. This approach assumes, however, that $V_{\mathrm{R} x}$ and $V_{\mathrm{R} y}$ are completely uncoupled, which seems less realistic than the proposed method with shear redistribution.

For simplicity, the total length $b_{x}$ and $b_{y}$ (shown in Figure 12)

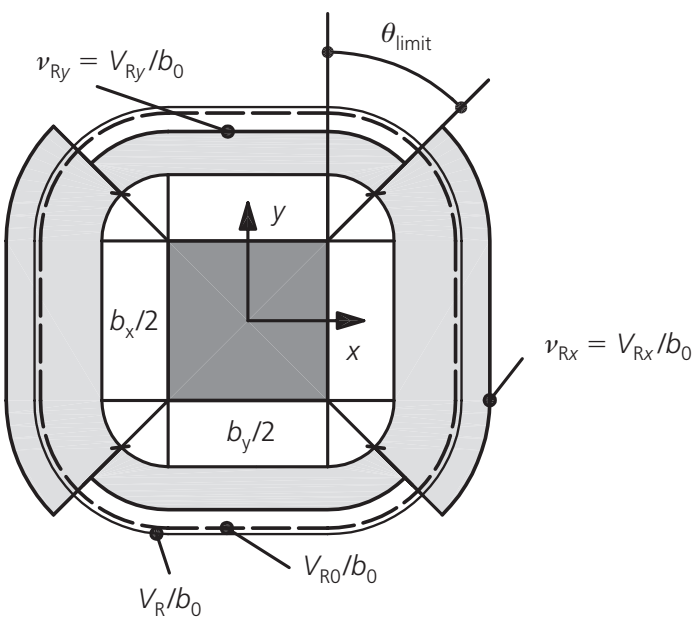

Figure 12. Simplified discretisation of control perimeter into $x-y$ segments; distribution of nominal shear strength and general notation can be generally taken in square columns as $b_{0} / 2$ (i.e. $\theta_{\text {limit }}=45^{\circ}$ ) when $V_{\mathrm{R} 0}<V_{\text {flex }}$. However, it was observed in experiments on slabs PT23 and PT33 (in which the flexural mechanism is developed fully $\left.\left(V_{\mathrm{R} 0}=V_{\text {flex }}\right)\right)$ that the redistribution capacity in such cases is limited due to the presence of wide flexural cracks. Hence, in slabs with low $\rho_{\min }$ or with $V_{\mathrm{R} 0}=V_{\text {flex }}$, the slab rotations at failure can be overestimated and use of a shorter segment $b_{x}\left(\theta_{\text {limit }}=90^{\circ}\right)$ is recommended in the analysis. This consideration, however, has no influence in the estimate of the failure load in such cases since $V=V_{\text {flex }}$.

\section{Analysis of test data using the proposed $\operatorname{CSCT}\left(\psi_{x}-\psi_{y}\right)$ method}

Figure 13(a) shows the predictions for PT34 (one-way loading) according to the $\operatorname{CSCT}\left(\psi_{x}-\psi_{y}\right)$ method using $V-\psi$ test data. Point $\mathrm{O}$ corresponds to the prediction according to $\operatorname{CSCT}\left(\psi_{\max }\right)$, point $\mathrm{B}$ shows the $V_{\mathrm{R} y}$ component after shear redistribution and point $\mathrm{C}$ is the predicted strength and maximum rotation according to $\operatorname{CSCT}\left(\psi_{x}-\psi_{y}\right)$. Point $\mathrm{C}$ is obtained when the redistributed shear in the $x$ direction reaches the failure criteria (point $\mathrm{B}^{*}$ ), assuming shear softening in the $y$ direction. Figure 13(a) is a practical way of illustrating the redistribution of stresses and shows that the proposed method provides more accurate predictions of strength and deformations than $\operatorname{CSCT}\left(\psi_{\max }\right)$.

The results shown in Figure 13(a) were obtained using the experimental load-rotation data. In design, the load-rotation relationships $\left(V-\psi_{y}\right.$ and $\left.V-\psi_{x}\right)$ need to be assessed by means of NLFEA or simplified formulas. Equation 5 was originally developed for axis-symmetrical slabs and non-symmetrical slabs using $V-\psi_{\max }$. In this work, it is proposed to estimate the load-rotation relationship corresponding to the lowest rotation $\left(\psi_{x}\right)$ using Equation 5 with $V_{\text {flex } x}$ corresponding to the flexural mechanism in the $x$ direction. Figure 13(b) shows that this approach can provide reasonable predictions, but further research is needed to adapt Equation 5 to more general cases of non-symmetrical slabs with different span lengths and reinforcement layouts.

The experimental tests were analysed using the proposed $\operatorname{CSCT}\left(\psi_{x}-\psi_{y}\right)$ method with two types of predictions of the $V-\psi$ curves. First, a refined estimation was carried out with NLFEA and considering flexural hardening $\left(V>V_{\text {flex }}\right)$ using Equation 15, which is derived in the Appendix. In the second analysis, which is denoted as 'simplified', Equation 5 was applied with a horizontal cut-off at $V_{\text {flex }}$ (i.e. flexural hardening is neglected). In both the simplified and refined approaches, the ratio $\Delta \psi_{y} / \Delta \psi_{x}$ was taken as 10 after the slab reached flexural capacity. This value is consistent with both the experimental data and with analytical predictions by the authors (shown in the Appendix).

Figure 13(b) shows that the redistribution of shear stresses predicted in the simplified analysis was comparable to that obtained using the experimental $V-\psi$ data. Figure 14 and Table 3 show that the strength predictions of the proposed $\operatorname{CSCT}\left(\psi_{x}-\psi_{y}\right)$ method considering $\psi_{x}$ and $\psi_{y}$ are as accurate as the EC2 and 


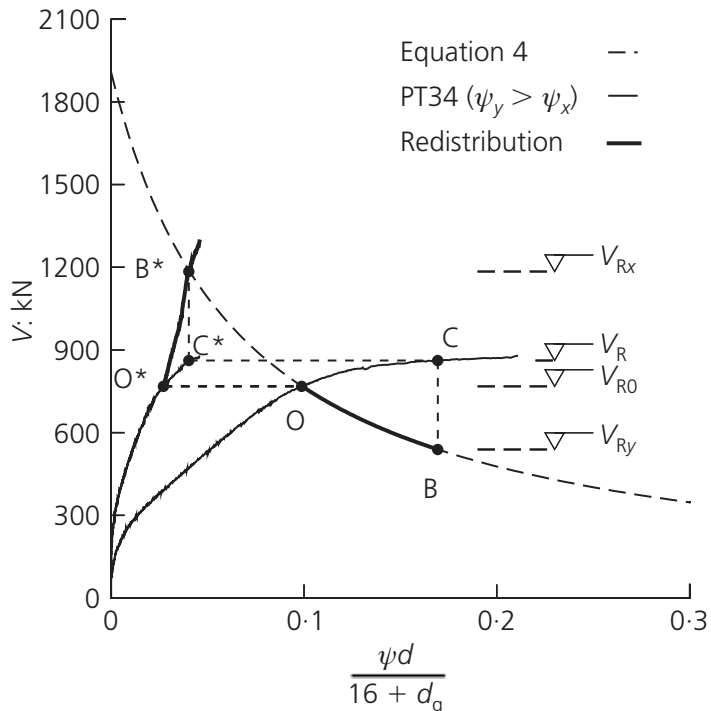

(a)

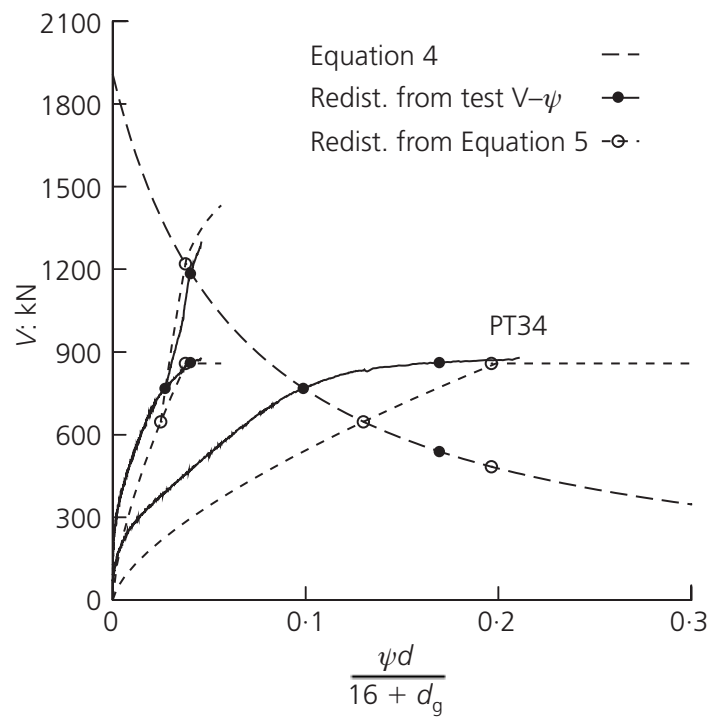

(b)

Figure 13. Predictions from the proposed method with stress redistribution and simplified discretisation. Results for specimen PT34 using (a) experimental load-rotation curves and

(b) simplified Equation 5 for $V-\psi_{x}$ and $V-\psi_{y}$

BS 8110 predictions. The proposed approach also provides useful information on the deformation capacity of the slab in terms of slab rotations. Moreover, the proposed approach with shear redistribution gives a physical explanation behind the assumption in the EC2 and BS 8110 formulas that consider both $x$ and $y$ directions to estimate the punching strength.

\section{Conclusions}

This paper has presented a general analytical approach to give accurate predictions of both punching strength and rotation capacity of slabs without transverse reinforcement and non-axis-

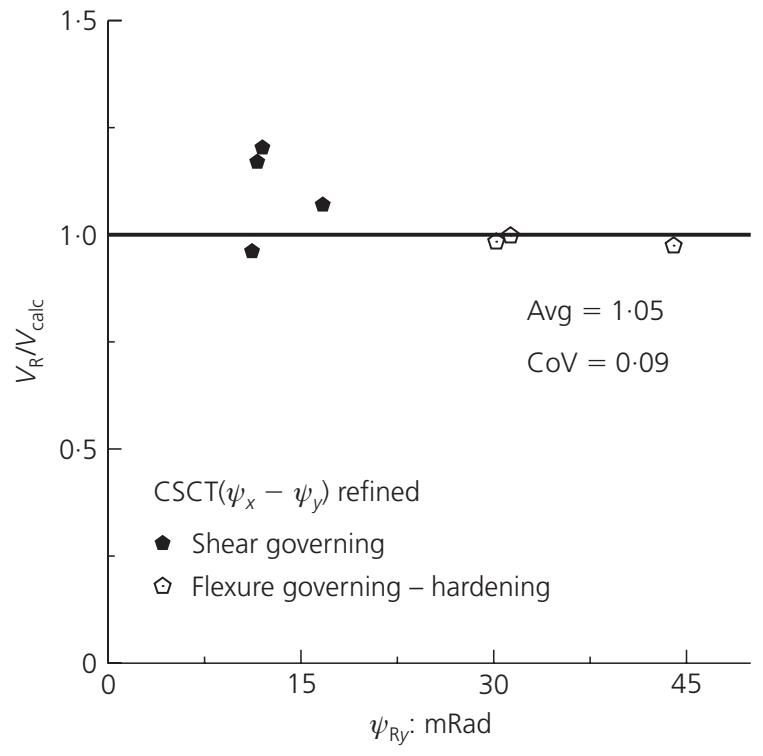

Figure 14. Punching shear strength predictions according proposed $\operatorname{CSCT}\left(\psi_{x}-\psi_{y}\right)$ method with refined estimation of the load-rotation relationships (data points from left to right: PT21, PT31, РT32, РT22, РT33, РT34, РT23)

symmetrical behaviour. This can be particularly useful for the design and analysis of slab bridges and flat slabs with rectangular bays, where slab deflections are non-symmetrical. The proposed model is consistent with the critical shear crack theory, which was originally developed for axis-symmetrical cases.

The main conclusions from the analytical study are as follows.

(a) The novelty of the proposed method is that it considers a non-uniform nominal shear strength distribution along the control perimeter. This assumption seems more realistic than current design methods, which assume axis-symmetrical conditions.

(b) The consideration of non-uniform strength along the perimeter allows a redistribution of shear near failure with a shear softening at the face of the control perimeter corresponding to the maximum rotations. The redistribution capacity can be limited in slabs in which the flexural capacity has clearly been reached due to the formation of wide flexural cracks.

(c) EC2 and BS 8110 formulas for punching provided accurate predictions of the strength of the specimens tested, which are comparable to the CSCT predictions using $\psi_{x}$ and $\psi_{y}$. The proposed approach provides a physical explanation behind averaging the strength contributions from the $x$ and $y$ directions. Although simple, the ACI 318-08 formula produced the largest scatter in the predictions; this is to be expected since flexural reinforcement is neglected.

(d) The simplified $\operatorname{CSCT}\left(\psi_{\max }\right)$ approach, although providing slightly more conservative predictions, seems practical for 


\begin{tabular}{|c|c|c|c|c|c|c|c|c|c|}
\hline & \multirow[t]{2}{*}{ Response } & \multirow{2}{*}{$\begin{array}{c}\psi_{\mathrm{R} y}-\psi_{\mathrm{R} x} \\
\text { mRad }\end{array}$} & \multirow{2}{*}{$\begin{array}{l}V_{R}: \\
k N\end{array}$} & \multirow[t]{2}{*}{$V_{\mathrm{R}} / V_{\text {flex }}$ * } & \multicolumn{3}{|c|}{$V_{\mathrm{R}} / V_{\text {calc }}$} & \multicolumn{2}{|c|}{$V_{R} / V_{\operatorname{CSCT}\left(\psi_{x}-\psi_{y}\right)}$} \\
\hline & & & & & $\mathrm{ACl}$ & EC2 & BS 8110‡ & Simplified & Refined \\
\hline PT21 & Symmetric & $11 \cdot 2-9 \cdot 9$ & 959 & 0.75 & $1 \cdot 11$ & 0.93 & 0.97 & 1.05 & 0.96 \\
\hline РT22 & Symmetric & $16 \cdot 7-14 \cdot 4$ & 989 & 0.83 & $1 \cdot 12$ & 1.05 & $1 \cdot 12$ & $1 \cdot 25$ & 1.07 \\
\hline PT23 & Non-symmetric & $44 \cdot 0-8 \cdot 5$ & 591 & $1 \cdot 14$ & $1 \cdot 14+$ & $1 \cdot 14+$ & $1 \cdot 14+$ & $1 \cdot 14+$ & $0.97 \S$ \\
\hline РT31 & Symmetric & $11 \cdot 6-9 \cdot 5$ & 1433 & 0.60 & $1 \cdot 46$ & $1 \cdot 11$ & $1 \cdot 30$ & $1 \cdot 25$ & $1 \cdot 17$ \\
\hline РT32 & Symmetric & $12 \cdot 0-10 \cdot 0$ & 1157 & 0.82 & 1.49 & $1 \cdot 17$ & $1 \cdot 23$ & $1 \cdot 31$ & $1 \cdot 20$ \\
\hline РT33 & Non-symmetric & $30 \cdot 2-8 \cdot 7$ & 602 & $1 \cdot 12$ & $1 \cdot 12+$ & $1 \cdot 12+$ & $1 \cdot 12+$ & $1 \cdot 12 \dagger$ & $0.98 \S$ \\
\hline РT34 & Non-symmetric & $31 \cdot 3-6 \cdot 9$ & 879 & 1.02 & $1.02+$ & $1.02+$ & $1.02+$ & 1.03 & $1.00 \S$ \\
\hline \multicolumn{2}{|c|}{ Average } & & & & $1 \cdot 21$ & 1.08 & $1 \cdot 13$ & $1 \cdot 16$ & 1.05 \\
\hline \multicolumn{2}{|c|}{ Minimum } & & & & 1.02 & 0.93 & 0.97 & 1.03 & 0.96 \\
\hline \multicolumn{2}{|c|}{ Coefficient of variation (CoV) } & & & & 0.15 & 0.08 & $0 \cdot 10$ & 0.09 & 0.09 \\
\hline
\end{tabular}

* $V_{\text {flex }}$ is estimated using the yield-line method

$+V_{\text {flex }}$ is governing $\left(V_{\text {calc }}=V_{\text {flex }}\right)$

₹ BS 8110: a conversion factor of 1.25 was applied for estimating $f_{\mathrm{Cu}}$ from the cylinder tests; no limitation on the concrete strength is applied

$\S$ Steel hardening was considered using Equation 15

Table 3. Predictions of slabs tested using different design

equations for punching shear ( $\mathrm{ACl}$ 318-08, EC2 and BS 8110)

and the proposed $\operatorname{CSCT}\left(\psi_{x}-\psi_{y}\right)$ method

design purposes, especially if reasonable estimations for the $V-\psi$ relationship are used.

(e) Shear stress fields analysis accounting for plastic redistribution due to bending showed that the shear stress for loads below punching failure can be uniform along the perimeter, even in slabs with non-symmetrical loading conditions (one-way loading) and deformations $\left(\rho_{y}<\rho_{x}\right.$ ).

The main findings from the test programme can be summarised as follows.

(a) The slabs tested in this work with $\rho_{x}>\rho_{y}$ showed that flexural reinforcement has a significant influence on the punching strength and symmetry of the response.

(b) Tests on specimens with symmetrical loading and a sufficiently large value of $\rho_{y}$ with $V_{\mathrm{R}}<V_{\text {flex }}$ had an almost symmetrical response, regardless of the fact that $\rho_{x} / \rho_{y}=2$.

(c) Specimens with a low value of $\rho_{y}(0 \cdot 3 \%)$ showed a punching failure with asymmetrical behaviour due to the formation of a plastic hinge. A slight increase in strength was observed in the tests with respect to $V_{\text {flex }}$ due to strain hardening of the flexural reinforcement. This can be taken into account using the model proposed here.

\section{Appendix: Slab rotations after plastic hinge formation}

Specimens PT23, PT33 and PT34 showed flexural hardening behaviour before failing in punching once the slab reached $V_{\text {flex }}$. This slight increase in strength with respect to $V_{\text {flex }}$ was due to the formation of a plastic hinge along the $x$ direction. This was followed by a significant increase in the slab rotation $\psi_{y}$, accompanied by a widening of the flexural cracks and strain hardening of the flexural reinforcement. In order to model this behaviour, the bond-slip between the concrete and the reinforcement bar needs to be taken into account. The square-root model for bond-slip described by Fernández Ruiz et al. (2007) was adopted to estimate the crack opening in the elastoplastic domain $\left(\varepsilon_{\mathrm{s}}>\varepsilon_{\mathrm{y}}\right)$. This model generally provides more accurate predictions than rigid-plastic models (Fernández Ruiz et al., 2007). For simplicity, the local loss of bond stiffness and strength due to the formation of diagonal cracks near the reinforcement bar was neglected. A bilinear strain-stress relationship was adopted for the steel reinforcement with a hardening modulus of steel $E_{\mathrm{sh}}$ equal to $1 \cdot 10 \mathrm{GPa}$, which was obtained experimentally.

These considerations led to the following proposed equations, which assume that the crack opening is proportional to the slab rotation by a factor of $(d-x)$ (Figure 15(a)), where $x$ is the height of the compression zone from plasticity.

12. $\psi_{y}=\psi_{\mathrm{flex}, y}+\lambda\left[\ln \left(\frac{\varepsilon_{\mathrm{bu}}-\varepsilon_{\mathrm{y}}}{\varepsilon_{\mathrm{bu}}-\varepsilon_{\mathrm{s}}}\right)-\left(\frac{\varepsilon_{\mathrm{s}}-\varepsilon_{\mathrm{y}}}{\varepsilon_{\mathrm{bu}}}\right)\right]$ 


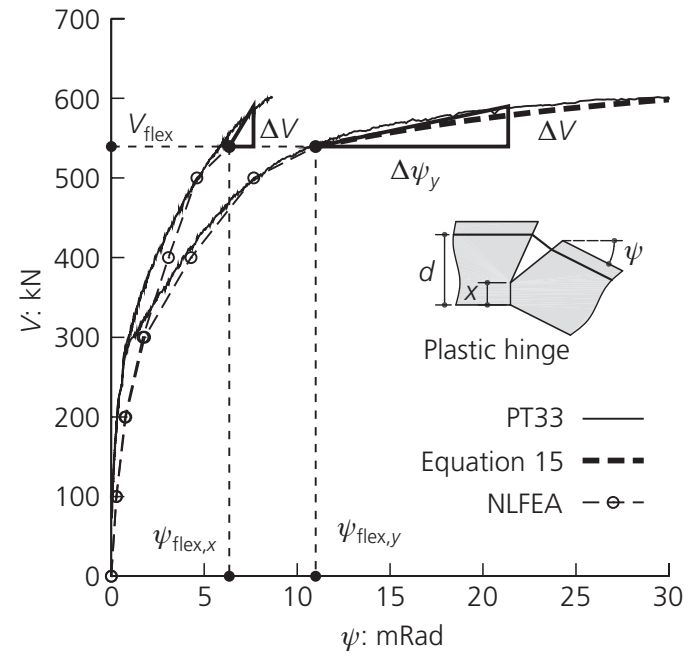

(a)

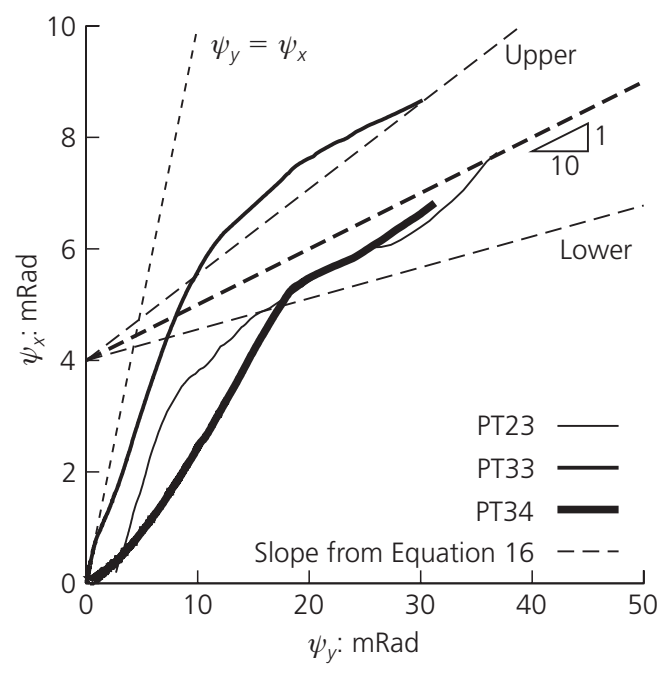

Figure 15. Slab rotations after the development of a plastic hinge: (a) experimental and predicted flexural hardening behaviour in specimen PT33; (b) $\psi_{y}-\psi_{x}$ in PT23, PT33 and PT34

14. $\lambda=\frac{E_{\mathrm{sh}} \varphi_{\mathrm{s}} \varepsilon_{\mathrm{bu}}\left(\varepsilon_{\mathrm{bu}}-\varepsilon_{\mathrm{y}}\right)}{2 \tau_{\mathrm{bmax}}(d-x)}$

where $\varepsilon_{\mathrm{y}}$ is the steel strain at yielding $(0 \cdot 27 \%), \varepsilon_{\mathrm{bu}}$ is the bond ultimate strain $(8.8 \%), \phi_{\mathrm{s}}$ is the diameter of the reinforcement bar, $\tau_{\text {bmax }}$ is the maximum bond stress, which was taken as $f_{\mathrm{c}}^{2 / 3}$ (Fernández Ruiz et al., 2007) and $\psi_{\text {flex, } y}$ is the slab rotation in the $y$ direction corresponding to $V_{\text {flex }}$ (Figure 15(a)). For simplicity, the second term in the multiplier of $\lambda$ in Equation 12 is neglected for large plastic deformations. This simplification allows solving for $V$ in Equations 12 and 13, leading to

$$
V=V_{\text {flex }}\left[1+\frac{E_{\text {sh }}}{f_{\mathrm{y}}}\left(\varepsilon_{\mathrm{bu}}-\varepsilon_{\mathrm{y}}\right)\left(1-\mathrm{e}^{-\left(\psi_{y}-\psi_{\text {flex }, y}\right) / \lambda}\right)\right]
$$

Figure 15(a) shows the development of the slab rotation after the formation of the plastic hinge in test PT33, which was reproduced satisfactorily using the proposed Equation 15. Similar results were obtained for specimens PT23 and PT34.

The authors estimated analytically the ratio between the rotation increments $\Delta \psi_{y} / \Delta \psi_{x}$ corresponding to a load increment $\Delta V$ from $V_{\text {flex }}$ shown in Figure 15(a). The ratios $\Delta V / \Delta \psi_{x}$ and $\Delta V / \Delta \psi_{y}$ were estimated using Equations 5 and 15 respectively, leading to Equation 16 for cases where $V_{\text {flex }, x}>V_{\text {flex, } y}$

16. $\frac{\Delta \psi_{y}}{\Delta \psi_{x}} \approx\left(\frac{E_{\mathrm{s}} \varphi_{\mathrm{s}} \varepsilon_{\mathrm{bu}}}{4 \cdot 5 \tau_{\mathrm{bmax}} r_{\mathrm{s}}}\right)\left(\frac{d}{d-x}\right)\left(\frac{V_{\mathrm{flex}, x}}{V_{\mathrm{flex}, y}}\right)^{3 / 2}$

Equation 16 was applied to tests on specimens PT23, PT33 and PT34. Figure 15(b) shows the upper and lower bound predictions obtained for $\Delta \psi_{y} / \Delta \psi_{x}$, which are in good agreement with the experimental data. For simplicity, the ratio $\Delta \psi_{y} / \Delta \psi_{x}$ can be taken as a constant value equal to 10 for the tests presented in this paper, as shown in Figure 15(b).

\section{REFERENCES}

ACl (American Concrete Institute) (2008) ACI-318-08: Building code requirements for structural concrete and commentary. ACI, Farmington Hills, MI.

BSI (British Standards Institution) (1972) CP 110: The structural use of concrete, part 1: design materials and workmanship. BSI, London.

BSI (1997) BS 8110 Part 1: Structural use of concrete: code of practice for design and construction. BSI, London.

BSI (2004) EN-1992-1-1: 2004, Eurocode 2: design of concrete structures. Part 1, general rules and rules for buildings. BSI, London.

Concrete Society (2005) Post-Tensioned Concrete Floors: Design Handbook. Concrete Society, Camberley, Technical report no. 43.

Fernández Ruiz M, Muttoni A and Gambarova PG (2007) Analytical modelling of the pre- and post yield behavior of bond in reinforced concrete. Journal of Structural Engineering 133(10): 1364-1372.

Guandalini S, Burdet OL and Muttoni A (2009) Punching tests of slabs with low reinforcement ratios. ACI Structural Journal 106(1): 87-95.

Hallgren M (1996) Punching Shear Capacity of Reinforced High Strength Concrete Slabs. PhD thesis, KTH Stockholm, Sweden.

Kinnunen S and Nylander H (1960) Punching of concrete slabs without shear reinforcement. Transactions of the Royal Institute of Technology, Civil Engineering 3(158): 1-112.

Muttoni A (2008) Punching shear strength of reinforced concrete slabs without transverse reinforcement. ACI Structural Journal 105(4): 440-450.

Muttoni A and Fernández Ruiz M (2008) Shear strength of 
members without transverse reinforcement as a function of critical shear crack width. ACI Structural Journal 105(2): 163-172.

Muttoni A and Schwartz J (1991) Behaviour of beams and punching in slabs without shear reinforcement. IABSE Colloquium, Zurich 62: 703-708.

Papanikolaou KV, Tegos IA and Kappos AJ (2005) Punching shear testing of reinforced concrete slabs, and design implications. Magazine of Concrete Research 57(3): $167-$ 177.

Regan P (1986) Symmetric punching of reinforced concrete slabs. Magazine of Concrete Research 38(136): 115-128.

SIA (Swiss Society of Engineers) (2003) SIA 262: Code for concrete structures. SIA, Zurich.
Sagaseta J, Fernández Ruiz M and Muttoni A (2009) Non-symmetrical punching of flat slabs and slab bridges without transverse reinforcement. fib Symposium, London. The Concrete Society, London.

Tassinari L, Muttoni A and Fernández Ruiz M (2008) Punching Shear Tests on Reinforced Concrete Slabs with Non-symmetrical Reinforcement. EPFL-IS-Beton, Lausanne (in French).

Vaz Rodrigues R (2007) Shear Strength of Reinforced Concrete Bridge Deck Slabs. PhD thesis, École Polytechnique Fédérale de Lausanne, Lausanne.

Vaz Rodrigues R, Fernández Ruiz M and Muttoni A (2008) Shear strength of R/C bridge cantilever slabs. Engineering Structures 30(11): 3024-3033.

\section{WHAT DO YOU THINK?}

To discuss this paper, please submit up to 500 words to the editor at www.editorialmanager.com/macr by 1 December 2011. Your contribution will be forwarded to the author(s) for a reply and, if considered appropriate by the editorial panel, will be published as a discussion in a future issue of the journal. 